$\int_{0}^{2}$ CHOICE

\title{
Current issues in diagnostic breast pathology
}

\author{
Rosemary A Walker, ${ }^{1}$ Andy Hanby, ${ }^{2}$ Sarah E Pinder, ${ }^{3}$ Jeremy Thomas, ${ }^{4}$ \\ lan 0 Ellis, ${ }^{5}$ National Coordinating Committee for Breast Pathology Research \\ Subgroup, On behalf of members of the National Coordinating Committee for \\ Breast Pathology
}

${ }^{1}$ Cancer Studies and Molecular Medicine, University of Leicester, Leicester, UK ${ }^{2}$ Academic Unit of Pathology, Leeds University, Leeds, UK

${ }^{3}$ Academic Oncology/Breast Pathology, King's College London, London, UK ${ }^{4}$ Department of Pathology, Western General Hospital, Edinburgh

${ }^{5}$ Molecular Medical Sciences, University of Nottingham, Nottingham, UK

\section{Correspondence to}

Dr lan 0 Ellis, Molecular Medical Sciences, University of Nottingham, Department of Histopathology, Nottingham City Hospital, Hucknall Road, Nottingham NG7 1DD, UK; ian.ellis@nottingham.ac.uk

Accepted 1 February 2012 Published Online First 19 July 2012

\section{ABSTRACT}

On behalf of the NHS Breast Screening Programme Pathology Coordinating Group we present recommendations for terminology and diagnostic criteria for a number of key areas of practice in breast pathology where terminology can be confusing and where accurate communication will ensure appropriate clinical management. These recommendations cover columnar cell lesions and the spectrum of changes that can be seen in these epithelial proliferations, lobular neoplasia, micrometastases and isolated tumour cells in axillary lymph nodes, the use of basal/myoepithelial markers in diagnostic practice and oestrogen receptor testing in ductal carcinoma in situ.

\section{INTRODUCTION}

The research subgroup of the NHS Breast Screening Programme (NHSBSP) Pathology Coordinating Group have compiled overviews and recommendations for topics that were either not considered or had minimal discussion in NHSBSP publication number 58 Pathology Reporting of Breast Disease. These will be included as appendices in the pending revision of the non-operative reporting guidelines. In conjunction with NEOAS the HER2 reporting guidelines have been updated and published: Walker RA, Bartlett JM, Dowsett M, et al. HER2 testing in the UK: further update to recommendations. J Clin Pathol 2008;61:818-24.

These topics are emerging issues in diagnostic breast pathology and are presented below as a series of short monographs.

\section{COLUMNAR CELL LESIONS: NHSBSP COORDINATING GROUP RECOMMENDATIONS FOR TERMINOLOGY AND DIAGNOSTIC CRITERIA Background}

In recent years there has been growing interest and awareness of epithelium within breast biopsies having a columnar morphology. One of the common accompaniments of this change is the presence of secretions within lumina, which are often distinctly eosinophilic and associated with microcalcifications. ${ }^{1}$ These microcalcifications are detectable at mammography and consequently more of these lesions are being detected with the introduction and expansion of breast screening programmes.

The diverse terminology employed for this epithelium, its increased detection at screening and the uncertainties regarding its biology continue to cause concern among both diagnostic breast pathologists and their clinical colleagues in the breast care team. In this document, we present a proposal for a simplified terminology for lesions with columnar epithelium and histological criteria for recognising these, and recommendations for classification using the ' $\mathrm{B}$ ' grading system in core biopsies. These proposals are not set in stone and may change as more knowledge is acquired regarding the pathobiology of these lesions and their relationship to malignancy.

\section{Terminology}

It should be noted that a columnar/flat morphology is often seen in the epithelium of benign breast lesions outside the columnar change/flat epithelial atypia (FEA) spectrum and in cytological preparations from a number of conditions, for example, intraductal papillomas. ${ }^{2}$ Tall columnar cells are also a feature of a number of more unusual carcinoma variants, for example, a tumour recently described as resembling the tall cell variant of papillary thyroid carcinoma. ${ }^{3}$

Here we refer to a group of lesions deduced by several authors to lie within the constellation of fibrocystic change. ${ }^{4}$ Within this group, a more focused spectrum of lesions has been delineatednamely, columnar cell change (CCC), CCC with hyperplasia, CCC with atypia and columnar cell hyperplasia with atypia. ${ }^{6}$ The morphology of those with atypia corresponds to FEA, as detailed in the latest WHO classification.

CCC $^{58-10}$ has been otherwise variously described and/or illustrated over the years and lesions with attributes of columnar lesion have been referred to under a great diversity of names. ${ }^{14} 711-23$ Some of these terms are detailed in figure 1. However, in assessing these it is worth noting, as Ho et al comment, that 'one must be extremely careful when comparing outcome of FEA and its equivalents in the literature, without first having determined if authors are referring to the same lesion'. 23 This statement equally applies to all forms of the overlapping columnar cell lesions (CCLs).

The proposed ductal intraepithelial neoplasia (DIN) spectrum described by Bratthauer et al ranges from usual type ductal hyperplasia through to high-grade ductal carcinoma in situ (DCIS), ${ }^{24}$ although molecular studies do not support this as a continuum and this system of classification is not widely used. The territory mapped out relevant to the present discussion is the DIN 1-flat type which equates to $\mathrm{FEA}^{24}$

More recently, terminological practice has been generally simplified (figure 2), reflecting current guidelines. 


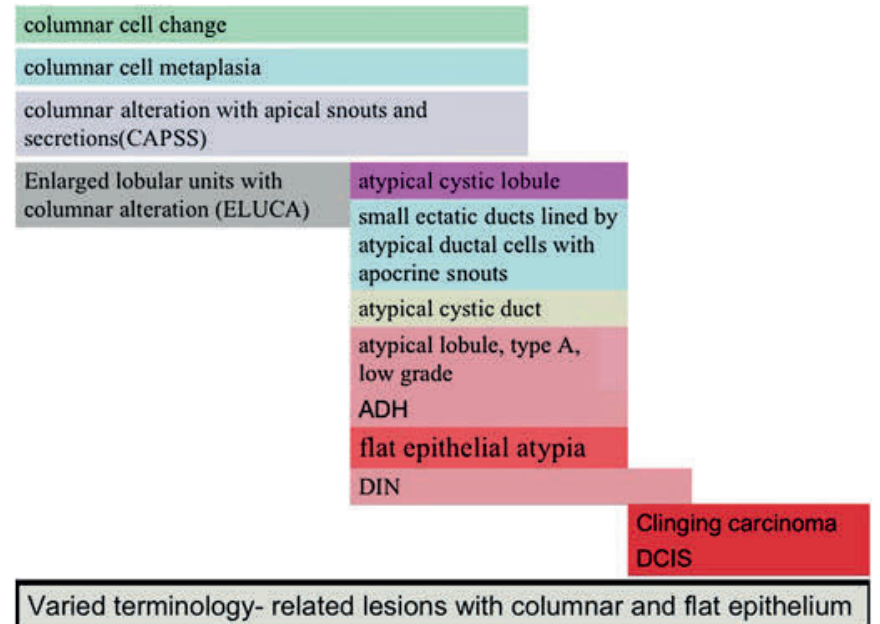

Figure 1 Varied terminology-related lesions with columnar and flat epithelium. ADH, atypical ductal hyperplasia; DCIS, ductal carcinoma in situ; DIN, ductal intraepithelial neoplasia.

\section{Microscopic appearances of CCLs (Table 1) CCCs without atypia}

The classic CCL is comprised of lobular acini lined by epithelial cells that are tall and snouted in a manner similar to that observed in tubular carcinoma. Commonly this is associated with luminal secretions and/or microcalcifications (figure 3A,B). If there is a piling up of several layers the term 'columnar cell hyperplasia' is used, assuming that the stratification is real (figure 3D) rather than artefactual as a consequence of crosscutting (figure $3 \mathrm{C}$ ). There is morphological diversity within these groups, for example, the hyperchromasia of the nuclei can vary, as well as nuclear shape and the 'tallness' of the cells; thus in some cases some lesions are more cuboidal than columnar.

\section{Flat epithelial atypia}

If cytological atypia is present in CCC or columnar cell hyperplasia, the lesions should be classified as FEA (figure 2). ${ }^{833}$ There is, however, morphological diversity in this group of lesion; in some cases the atypia manifests as relatively uniform rounded evenly spaced nuclei with a similar cytomorphology to that

\begin{tabular}{|c|l|}
\hline \multicolumn{2}{|c|}{ Columnar cell change } \\
\hline $\begin{array}{l}\text { Columnar cell } \\
\text { hyperplasia }\end{array}$
\end{tabular}
$\mathrm{B} 1 / 2$

\begin{tabular}{|c|}
\hline $\begin{array}{l}\text { Atypical ductal } \\
\text { hyperplasia(complex } \\
\text { architecture) }\end{array}$ \\
\hline $\begin{array}{l}\text { Flat epithelial atypia } \\
\text { (subsumes Atypical } \\
\text { Columnar cell change \& } \\
\text { atypical columnar cell } \\
\text { hyperplasia) }\end{array}$ \\
\hline (simple architecture) \\
\hline
\end{tabular}

B5a

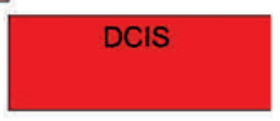

Most simple classification of columnar lesions (after Schnitt)

Figure 2 Most simple classification of columnar lesions (after Schnitt and Vincent-Salomon ${ }^{6}$ ). DCIS, ductal carcinoma in situ. displayed by the cells of low and some intermediate grade DCIS (figure 4C). In this form of FEA, polarisation of the cells may be lost. Nuclei are often more centrally placed. In others, distinct nuclear pleomorphism is evident, falling short of high nuclear grade but, equally, without the relative nuclear uniformity described above (figure 4A,B). Finally, some FEA display a distinctly endometrioid appearance with tightly packed tall hyperchromatic fusiform nuclei (figure 4D).

\section{Exclusions}

Atypical ductal hyperplasia

FEA by definition does not have a complex architecture; if micropapillary or cribriform structures are seen, the diagnosis of atypical ductal hyperplasia $(\mathrm{ADH})$ or low-grade DCIS should be considered. ${ }^{34}$ The process may involve more than one terminal duct lobular unit. Sporadic atypical architecture may be widely spaced. Rather than result in overdiagnosis of DCIS, it is proposed that the current size criterion guidelines for differentiating DCIS and $\mathrm{ADH}$ ( $>2 \mathrm{~mm}$ or $>2$ duct spaces) ${ }^{25}$ be relaxed and the term FEA be applied under these circumstances. Whether most FEA is biologically equivalent to most $\mathrm{ADH}$ is, as yet, uncertain but likely. In practice, FEA is often seen merging with the more elaborate architecture of $\mathrm{ADH}$ (figure 5) and DCIS, demonstrating the close relationship of FEA to these lesions. Lesions which fulfil the criteria for low-grade DCIS by showing $\geq 2$ ducts fully involved by an architecturally and cytologically atypical process without intervening gaps of non-atypical epithelium should still be regarded as such and not as FEA.

Ductal carcinoma in situ

Where flat epithelial proliferative epithelium within a terminal ductal lobular unit (TDLU) possesses high cytonuclear grade nuclei, the lesion should be categorised as high-grade flat DCIS, not FEA (figure 6). Care should be taken in the diagnosis of flat high-grade DCIS in core biopsies and it may be prudent to categorise this as B4 suspicious in such limited samples.

\section{Differential diagnosis}

It should be borne in mind that there are many phenomena with low or 'flat epithelium' that do not fall under the category of the CCLs-for example, the tall monolayered epithelium of in situ papillary neoplasia.

\section{Apocrine change}

Apocrine epithelium shares with columnar change the presence of apical snouts and sometimes associated secretions. However, the cytoplasm of apocrine cells is typically copious and granular and, unlike most columnar cells, nucleoli are readily seen. Apocrine cells are usually androgen receptor positive but oestrogen receptor (ER) and progesterone receptor (PR) negative; the converse is true for columnar epithelium.

\section{Lactational change}

Another lesion that may be mistaken for FEA is focal lactational change, which may appear both monolayered and mildly cytologically atypical with enlarged hyperchromatic nuclei. Typically, the epithelial cells are more cuboidal than tall and the foamy appearance to the cytoplasm produced by finely divided lipid should alert the pathologist to this diagnosis (figure 7).

\section{Markers in CCLs}

Producing a clear idea of the marker profile in columnar lesions is bedeviled by the variety of terminology used in different 
Table 1 Comparison of pathological features of the spectrum of entities from columnar cell change through to ADH/DCIS

\begin{tabular}{|c|c|c|c|c|}
\hline \multirow[b]{2}{*}{ Feature } & \multicolumn{4}{|l|}{ Diagnosis } \\
\hline & Columnar cell change & Columnar cell hyperplasia & FEA & ADH/DCIS \\
\hline Topography & $\begin{array}{l}\text { TDLU, acini may be mildly } \\
\text { dilated or of normal size }\end{array}$ & $\begin{array}{l}\text { TDLU, acini may be mildly } \\
\text { dilated or of normal size }\end{array}$ & $\begin{array}{l}\text { TDLU, often microcystically } \\
\text { dilated acini }\end{array}$ & TDLU \pm adjacent ducts \\
\hline Shape of acinar spaces & Irregularly shaped luminal margin & Irregularly shaped luminal margin & $\begin{array}{l}\text { Often rounded acinar spaces, } \\
\text { with smooth inner margin }\end{array}$ & $\begin{array}{l}\text { Often rounded acini, but with } \\
\text { complex structures extending } \\
\text { into lumen (see architecture, } \\
\text { below). }\end{array}$ \\
\hline Architecture & Flat & Tufts and mounds & Flat or tufted, not complex & $\begin{array}{l}\text { Complex with micropapillary } \\
\text { or cribriform structures }\end{array}$ \\
\hline Stratification/multilayering & Not present & Present & May be present & May be present \\
\hline $\begin{array}{l}\text { Luminal secretions often } \\
\text { with microcalcification }\end{array}$ & Present & Present & Present & May be present \\
\hline Nuclear size & Small to medium & Small to medium & Small to medium & Small to medium \\
\hline Nuclear shape & Oval, elongated & Oval, elongated & Often, but not always, rounded & Rounded \\
\hline Nuclear texture & Bland & Bland & $\begin{array}{l}\text { Speckled chromatin pattern } \\
\text { may be present }\end{array}$ & $\begin{array}{l}\text { Speckled chromatin } \\
\text { pattern common }\end{array}$ \\
\hline Pleomorphism* & Uniform & Uniform & $\begin{array}{l}\text { Uniform to moderately } \\
\text { pleomorphic }\end{array}$ & Uniform \\
\hline Position of nuclei within cell & Basally placed & Basally placed & Often central & Central \\
\hline Nucleoli & Not conspicuous & Not conspicuous & $\begin{array}{l}\text { Not conspicuous, but may } \\
\text { be evident }\end{array}$ & $\begin{array}{l}\text { Not conspicuous, but may } \\
\text { be evident }\end{array}$ \\
\hline Mitoses & Generally absent & Generally absent & Generally scarce & Generally scarce \\
\hline Extent & May be focal or extensive & May be focal or extensive & $\begin{array}{l}\text { May be a focal area } \\
\text { within background of } \\
\text { non-atypical CCL }\end{array}$ & $\begin{array}{l}\text { May be focal area within } \\
\text { background of non-atypical } \\
\text { CCL. By definition ADH is } \\
\text { small/microfocal }\end{array}$ \\
\hline
\end{tabular}

*If marked pleomorphism, the lesion does not fall with the spectrum of CCLs but should be regarded as high-grade DCIS.

$\mathrm{ADH}$, atypical ductal hyperplasia; CCLs, columnar cell lesions; DCIS, ductal carcinoma in situ; FEA, flat epithelial atypia; TDLU, terminal ductal lobular unit.

publications and the uncertainty about their equivalence. What follows is a distillation of what is known, under the broad umbrella of the names indicated above.

Unlike the normal breast and usual ductal hyperplasia (UDH) where ER and PR staining is heterogeneous and limited to about $10-15 \%$ of cells, ${ }^{25}$ in CCC and related lesions there is extensive and uniform positivity of the nuclei of all lesional cells. ${ }^{4} 51520$
Most cells stain positively for keratin $19^{15}$ and osteoprotegerin ${ }^{26}$ and a high proportion stain for cyclin D1. ${ }^{15}$ Kusama et al demonstrated a Ki67 labelling index of $0.3 \%$ in columnar lesions versus $13.7 \%$ in adjacent DCIS. ${ }^{18}$ Unlike UDH, the lesional cells do not express basal markers such as CK5/6. ${ }^{27}$ As indicated above, immunohistochemistry (IHC) may be useful in separating apocrine from columnar epithelium, the former being
Figure 3 Columnar cell change without atypia (A-D) Columnar cell change affects lobular units which show variably dilated acini often with microcystic change and calcification (figure 3A, B). The lining epithelial morphology varies from low cuboidal to the classic columnar type with apical snouts (3C) In more florid cases the epithelium is multi-layered and classified as columnar cell hyperplasia without atypia (3D).
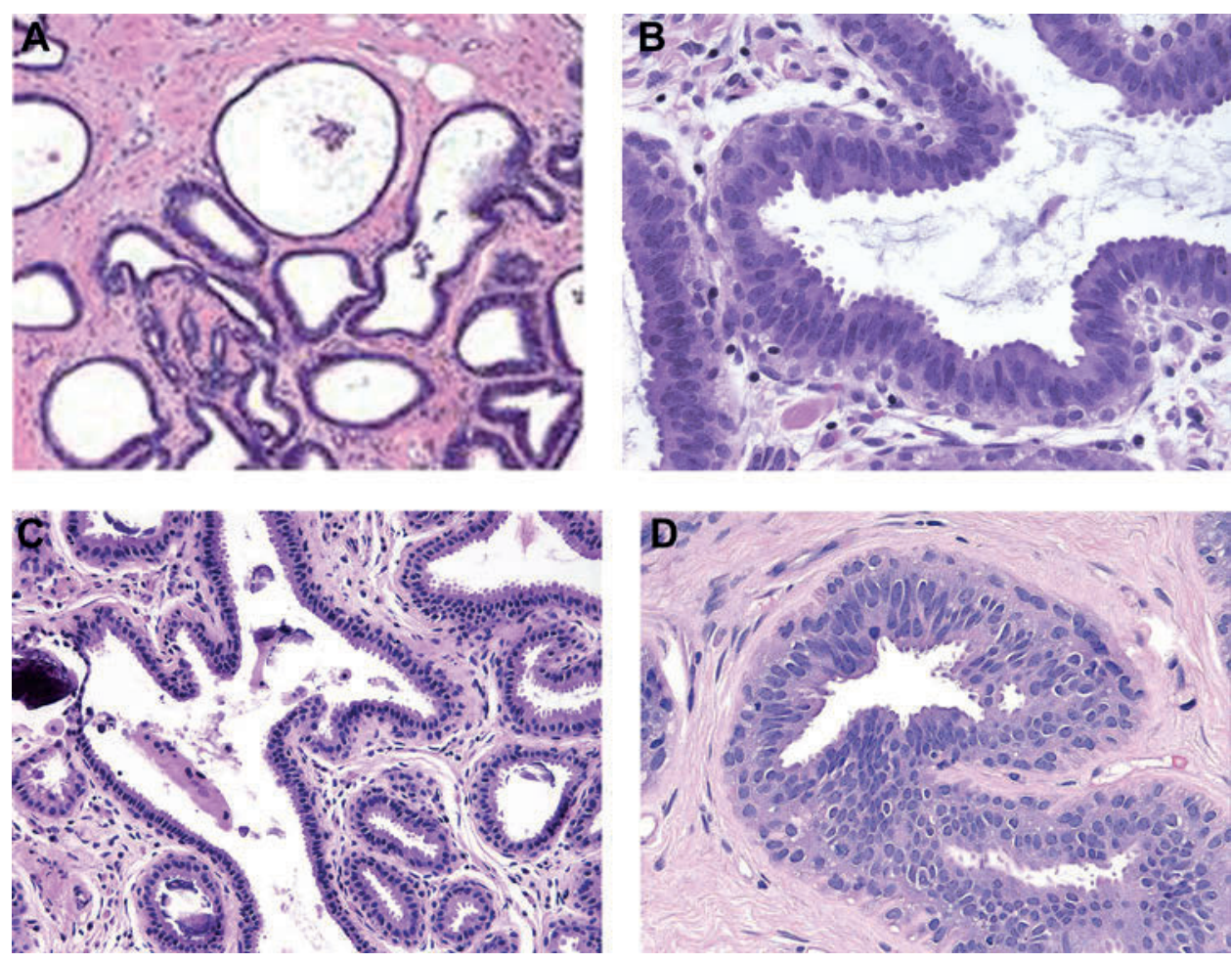
Figure 4 Flat epithelial atypia (4 A-D) Flat epithelial atypia usually shows more exajurated involvement of the breast parenchyma (4A). The cells show a loss of nuclear polarity but may retain a columnar morphology (4B). The nuclei are often more rounded and less ovoid than in columnar cell change (4C0. The degree of atypia can become more marked but is not high grade (4D)
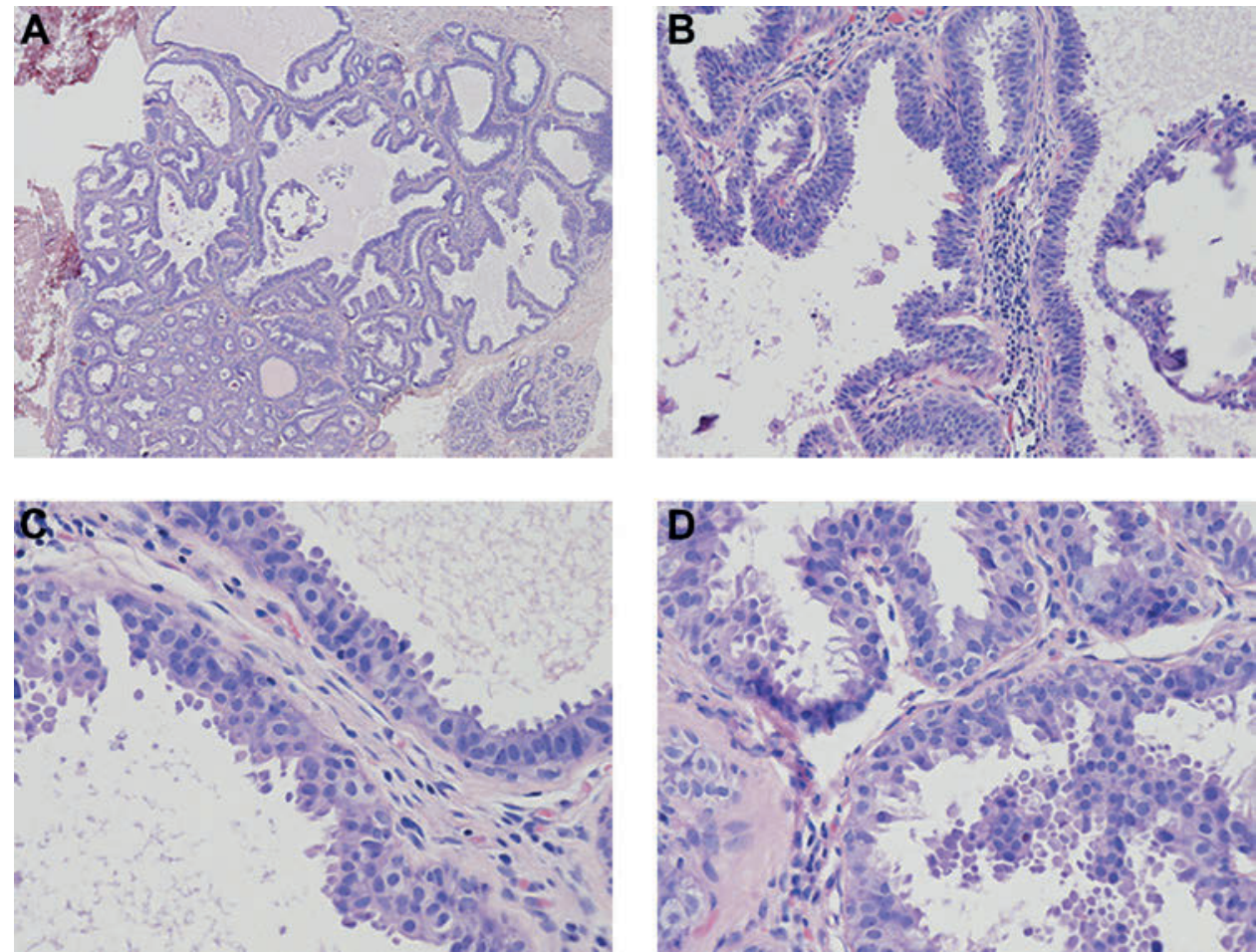

androgen receptor positive and ER and $\mathrm{PR}$ negative. The utility of GCF15, typically positive in apocrine epithelium, in making this distinction has yet to be documented in the literature. It is worth noting that McLaren et al found that patients with ER negative CCLs were at increased risk of malignancy compared with those whose lesions were ER positive, ${ }^{23}$ but as yet there are no confirmatory studies.

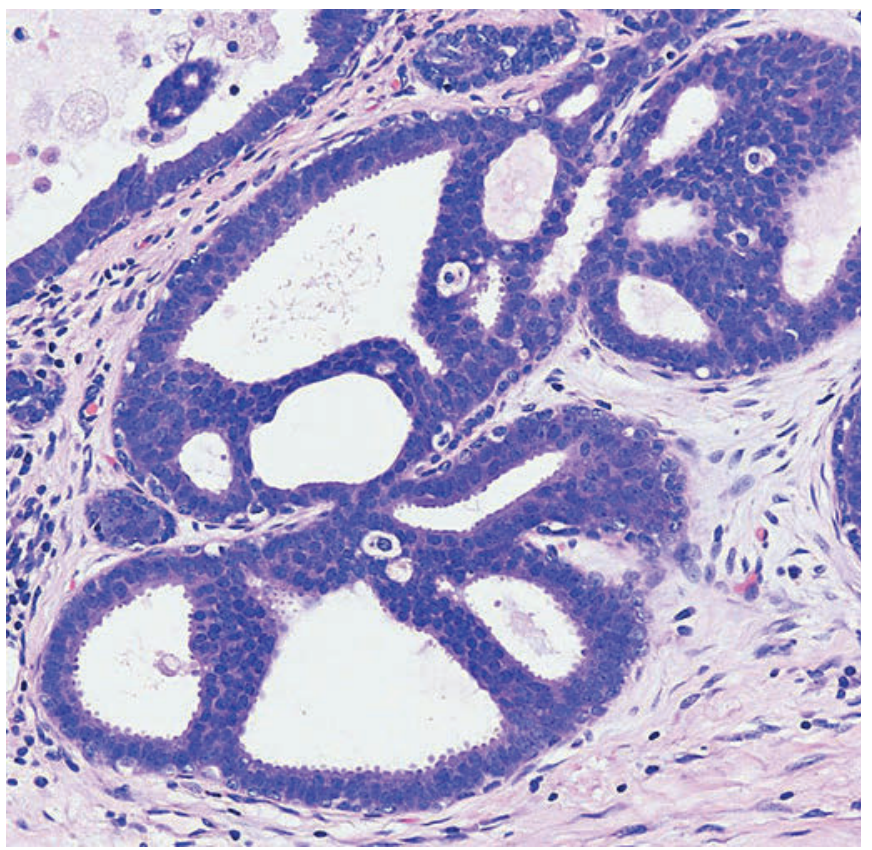

Figure 5 Atypical ductal hyperplasia. Flat epithelial hyperplasia, particularly when florid can show both cytonuclear and architectural feature of low grade DCIS but fail to have sufficcent extend for classification as DCIS. The diagnosis of atypical ductal hyperplasia arising in a background of FEA can be made in these circumstances.
In conclusion, at present the main use for $\mathrm{IHC}$ is in the differential diagnosis of columnar from some apocrine lesions.

\section{Significance of CCLs}

CCLs of the breast encompass a morphological spectrum which may coexist within a wide range of lesions that may include in situ and invasive carcinoma. ${ }^{9}$ However, the overall biological significance of these lesions is unknown. ${ }^{28}$ There is supporting evidence for a precursor role including an association with tubular carcinoma ${ }^{9}{ }^{12}$; the finding that these lesions are found more commonly in cancerous than non-cancerous breasts ${ }^{17}$; are often continuous with cancerous lesions ${ }^{18}$; commonly coexist with lobular in situ neoplasia ${ }^{22}$; and share similar cytological characteristics and immunohistochemical profile with coexistent malignancies. ${ }^{15}$

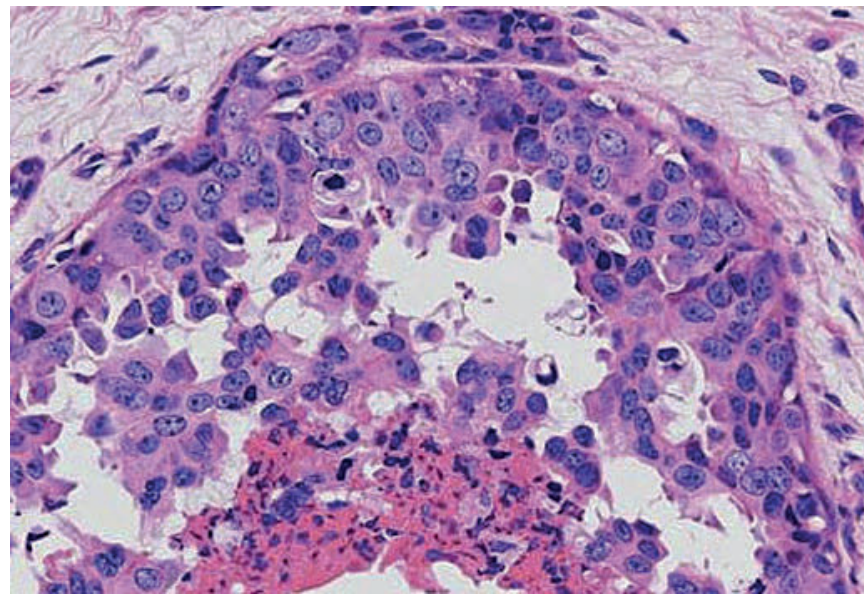

Figure 6 High-grade ductal carcinoma in situ may show mono- or oligo-layering within the inner surface of an involved duct. High-grade nuclear pleomorphism such as this is not seen in flat epithelial atypia. 
Figure 7 (A) Lactational changes can be mistaken for flat epithelial atypia and (B) in some rare variants show distinct cytological atypia. The epithelium tends to be cuboidal and the presence of foamy clear cytoplasm should alert one to this diagnosis.
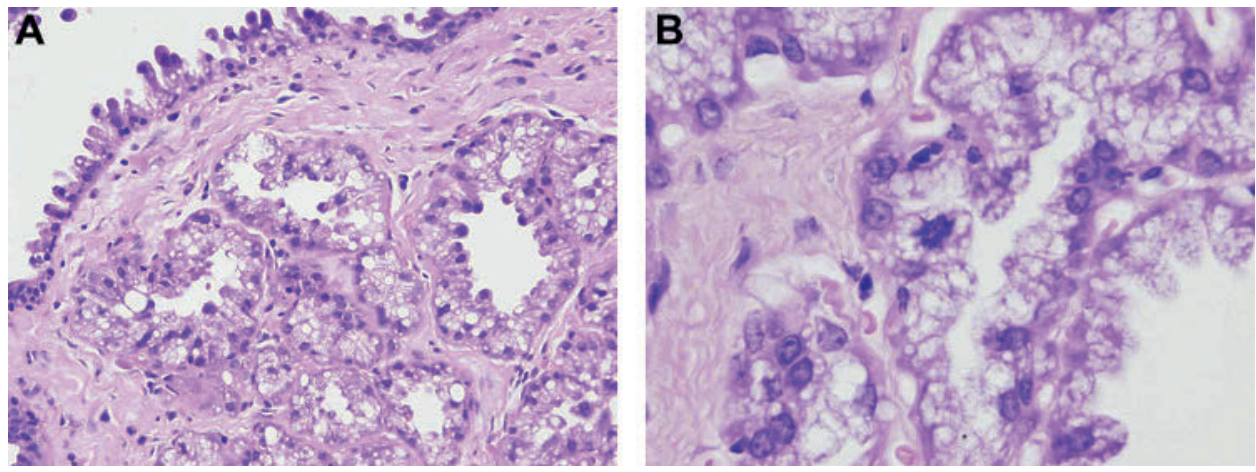

Despite the above, the certainty and speed of progression of these lesions to malignancy is unknown. Eusebi et al ${ }^{11}$ discovered 25 cases $(0.26 \%)$ of what was called low-grade clinging carcinoma of flat type, but which appears morphologically equivalent to FEA. During an average follow-up interval of 19 years, none of the 25 women with low-grade clinging carcinoma of flat type developed invasive carcinoma and only one had a recurrence, which was described as consisting of low-grade clinging carcinoma of flat type. ${ }^{29}$

At a more fundamental level, there is evidence that, in general, there is a progressive accumulation of allelic damage in FEA through to DCIS and invasive carcinoma, implying a molecular continuum from at least some lesions with a columnar morphology (which is not the case for UDH and carcinoma). ${ }^{28} 30$ Despite the very limited follow-up data to date and the need for more evidence, this implies that the biological progression of an individual columnar lesion may be slow. However, it seems very likely that FEA is one of the earliest forms of neoplastic change in the breast.

\section{CCLs in breast core biopsies}

Cores bearing CCLs are typically sampled for the histological assessment of mammographic microcalcifications. As for other such specimens, these should be examined at multiple levels (at least three). If CCC or hyperplasia only is found without atypia, the lesions should be regarded as within the constellation of fibrocystic change and categorised as B2, benign.

CCLs with atypia should be regarded as FEA and classified as B3, of uncertain malignant potential. Lesions with more complex architecture should also be regarded as an atypical epithelial proliferation and also regarded as B3, of uncertain malignant potential.

As for all such screen-detected lesions, multidisciplinary discussion should be undertaken to correlate radiological, clinical and histopathological findings. Data on risk of finding adjacent associated malignancy are extremely limited.

\section{CCLs in surgical excision specimens}

Thorough sampling and histological examination of surgical specimens bearing FEA should be performed to search for more established neoplasia. In association with some DCIS and/or invasive carcinoma, FEA may be present and may be extensive and/or may extend to the margins of the specimen. This is particularly problematic for lesions which are well recognised as being associated with FEA such as tubular carcinoma' and, in such cases, it may be uncertain as to whether the CCL represents the precursor process. There is a very limited evidence base for guidance but, at present, it is recommended that whole tumour size (DCIS plus invasive carcinoma) and margin status should include only those areas regarded as established DCIS or invasive tumour using conventional criteria.

\section{Reproducibility of current classification of CCLs}

The reproducibility of diagnosis of CCL varies in the published literature. One study looking at the assessment of images by a mixed population of assessors showed poor agreement. ${ }^{31}$ Another demonstrated 'excellent agreement' for a specified task within the CCL group after a PowerPoint directed training session undertaken by a group of pathologists with an interest in breast pathology. ${ }^{32}$ Agreement was slightly better for determining the absence of FEA (92.8\%, 95\% CI $84.1 \%$ to $97.4 \%)$ than for determining its presence $(90.4 \%, 95 \%$ CI $79.9 \%$ to $96.7 \%$ ). The latter authors concluded that the diagnosis of FEA and its distinction from CCLs without atypia was highly reproducible if the presently available diagnostic criteria were adhered to. This simplified classification in the latter study forms the basis of the recommendations presented here.

Issues of poor reproducibility can confound diagnosis and lead to inconsistent patient care. This is more likely when complex and diverse terminology with shades of possible interpretations exist. This is no more apparent than in the case of lesions possessing columnar epithelial morphology and is the strongest argument for the simplified classification of these lesions presented in this document.

\section{Key points and recommendations}

- The terms columnar cell change and columnar cell hyperplasia are regarded as benign lesions falling within the constellation of fibrocystic changes and in core biopsy should be classified as B2, benign.

- Columnar cell lesions with cytological atypia should be regarded as FEA and, in a core biopsy, categorised as B3, of uncertain malignant potential.

- Sporadic atypical architecture may be widely spaced. Rather than result in overdiagnosis of DCIS, it is proposed for the current guidelines that the size criterion for differentiating DCIS and ADH ( $>2 \mathrm{~mm}$ or $>2$ duct spaces) $)^{25}$ be relaxed and the term FEA be applied under these circumstances. In needle core biopsy samples these should be regarded as B3, of uncertain malignant potential.

- Columnar cell lesions with high cytonuclear grade should be regarded as flat high-grade DCIS.

\section{IN SITU LOBULAR NEOPLASIA: NHSBSP COORDINATING GROUP OVERVIEW AND RECOMMENDATIONS}

Lobular carcinoma in situ (LCIS) was first described in 1941 by Foote and Stewart ${ }^{33}$ and was considered to be akin to DCIS with 
regard to clinical behaviour, with the recommended management being mastectomy. Subsequently, lobular neoplasia, the term introduced by Haagensen et $a l^{34}{ }^{34}$ was felt to differ from DCIS, being a risk indicator of subsequent development of breast cancer $^{34-36}$ rather than a true precursor, so radical surgical treatment fell out of favour. The advent of mammographic screening, further follow-up studies and molecular analysis of lobular neoplasia has resulted in the need to re-address its significance and management.

\section{Terminology}

Atypical lobular hyperplasia (ALH) and LCIS have been considered distinct entities. They are both characterised by a proliferation within the TDLUs of poorly cohesive, monotonous cuboidal or polygonal cells with clear or light cytoplasm. Intracytoplasmic lumina may be present. Mitotic figures are infrequent. Pagetoid spread of cells between the surface epithelial cells and the basement membrane may be present. The differentiation between the two forms relates to the extent and degree of distension of acini, but this is subject to intra- and inter-observer variability. Because of this the term 'lobular neoplasia' or 'in situ lobular neoplasia' was introduced, which does not differentiate between ALH and LCIS.

A further system proposed is 'lobular intraepithelial neoplasia' ${ }^{37}$ with three subdivisions that relate to morphology and predicted clinical outcome. This grading system requires validation and has not been endorsed by the WHO at the present time. $^{38}$

'Pleomorphic lobular carcinoma in situ' is a more recently described entity ${ }^{39-42}$ in which the cells show more marked pleomorphism with larger nuclei. Central necrosis and calcification may be present. Distinction from high-grade DCIS may, on occasions, be difficult. Comedo-type necrosis can be present in LCIS that has the typical cytological and architectural features ${ }^{42}$ and, although atypical, this should not be diagnosed as pleomorphic LCIS.

Other variants that have been described include endocrine, apocrine, histiocytoid and signet ring lobular neoplasia, ${ }^{43}$ mainly based on cytonuclear features.

\section{Frequency}

It is difficult to assess the frequency of lobular neoplasia since there are no specific clinical, mammographic and macroscopic features. It was considered to be present more frequently in the 40-50 age group ${ }^{34}$ but the incidence in postmenopausal women is increasing, probably due to detection by mammographic screening. The incidence in otherwise benign biopsies is reported as between $0.5 \%$ and $3.8 \%{ }^{34}{ }^{44}$ It can be both multifocal and bilateral.

\section{Immunohistochemical analysis}

The characteristic alteration of lobular neoplasia is the lack of expression of the cell adhesion molecule E-cadherin, which is consistently present on the membranes of normal luminal epithelial cells and is also lost in invasive lobular carcinoma (ILC). ${ }^{45-47}$ Alterations are seen in both classical and pleomorphic lobular neoplasia and immunohistochemical analysis of E-cadherin can aid the diagnosis of solid in situ proliferations of indeterminate nature. ${ }^{48-50}$ Lack of E-cadherin supports a diagnosis of lobular neoplasia but, if a mixed pattern of staining is present, then it should be reported as combined DCIS and lobular neoplasia. ${ }^{50}$ Negative markers can, however, cause problems in interpretation. p120 catenin is a member of the cadherin-catenin complex that has a cytoplasmic staining pattern in lobular neoplasia and has been found to be useful in separating lobular neoplasia from low-grade DCIS. ${ }^{51}$

High molecular weight cytokeratins identified by the antibody $34 \beta E 12$ have been reported to be consistently present in lobular neoplasia and could be used to differentiate it from DCIS, ${ }^{52}$ but a subsequent report considered staining to be an artefact. ${ }^{53}$ This antibody should be used with caution.

Lobular neoplasia consistently shows positivity for ER and $\mathrm{PR}$, including the pleomorphic variant. ${ }^{41} 47$ HER2 amplification and overexpression have been found in pleomorphic LCIS. ${ }^{41} 42$

\section{Molecular studies}

The CDH1 gene that encodes for E-cadherin is inactivated in LCIS and ILC through both genetic (deletions and inactivating mutations) and epigenetic (gene promoter methylation) mechanisms. ${ }^{54-56}$ Concurrent mutations have been identified in LCIS and ILC. ${ }^{46}$ Mutations have also been found in ALH. ${ }^{56}$

Comparative genomic hybridisation analysis has shown that similar chromosomal changes are present in ALH and LCIS. ${ }^{57}$ Array comparative genomic hybridisation and mitochondrial DNA analyses have confirmed similar genetic alterations between matched lobular neoplasia and ILC. ${ }^{58} 59$

Overall, the molecular data provide strong evidence that lobular neoplasia is a non-obligate precursor of ILC.

\section{Differential diagnosis}

The main problems relate to poor fixation in a surgical specimen, differentiating low-grade solid DCIS from lobular neoplasia and pleomorphic LCIS.

In larger surgical specimens poor fixation can lead to artefactual discohesion within lobular units, resulting in an overdiagnosis of LCIS. This is more of a problem in mastectomies that have not been sliced sufficiently in the fresh state.

Differentiating low-grade solid DCIS from lobular neoplasia can be difficult in both surgical specimens and core biopsies and the use of E-cadherin staining can be particularly helpful. ${ }^{48-50}$ Coexistent low-grade DCIS and lobular neoplasia is not rare and a mixed pattern of E-cadherin staining will be seen in these circumstances. Cancerisation of lobules by DCIS can also cause problems and again E-cadherin staining is of value.

Pleomorphic LCIS $^{39-42}$ can be difficult to differentiate from high-grade DCIS due to the degree of pleomorphism, the presence of necrosis and calcification, and has most certainly been classified as DCIS previously. Pleomorphic LCIS should be considered if there is poor cellular cohesion along with these other features. Again E-cadherin staining can be invaluable.

Since it is not possible reliably to assess the degree or extent of lobular changes in core biopsies, providing that DCIS has been excluded, the lesion should be reported as B3, of uncertain malignant potential, and recorded as lobular neoplasia, with no attempt to distinguish ALH and LCIS.

\section{Significance}

The significance of the diagnosis of lobular neoplasia in a needle core biopsy relates to the risk of there being associated invasive carcinoma (or DCIS) present at the time of the biopsy (see Management). When identified within a surgical biopsy/excision specimen, the questions of concern are different. These are: (1) What is the risk of subsequent development of invasive carcinoma? (2) Is lobular neoplasia a precursor lesion of invasive disease? (3) Does lobular neoplasia affect the risk of recurrence following breast conserving therapy?

It has been recognised for a long time that lobular neoplasia is an indicator of increased risk of developing invasive cancer, ${ }^{34-3644}$ 
with the RR differing between ALH $(3-5 \times)^{60-62}$ and LCIS $(8-11 \times) .{ }^{34} 36446364$ The increased risk has been found in some reports to be evenly distributed between both breasts, ${ }^{34} 6465$ although Page et al ${ }^{62}$ found invasive carcinoma to be three times more likely to arise in the breast with ALH than the contralateral. Collins et $a l^{66}$ found the risk of developing an invasive cancer to be greater for premenopausal women with ALH than $\mathrm{ADH}$, whereas SEER data ${ }^{64}$ show an increased incidence after the menopause.

The evidence that lobular neoplasia could be a non-obligate precursor lesion comes from molecular and epidemiology studies. As described above, the genetic profiles of ALH and LCIS are similar to each other and to those of ILC. ${ }^{54-59}$ That there is a greater risk of invasive cancer in the ipsilateral breast ${ }^{626667}$ and that the invasive cancer is more likely to be lobular than ductal ${ }^{35}$ 67 also indicate that lobular neoplasia could be a non-obligate precursor. Although there are no long-term follow-up studies of pleomorphic LCIS, the small-size series that have been published have shown a higher incidence of associated invasive disease, usually ILC, which is suggestive of a precursor lesion. ${ }^{42}$

There is general agreement from published studies that the presence and extent of lobular neoplasia, including presence at the margins, does not increase the risk of recurrence following breast conserving surgery, ${ }^{68-71}$ although the NSABP study ${ }^{69}$ excluded cases of pleomorphic LCIS (described as DLCIS).

\section{Management}

Needle core biopsy

Issues relating to lobular neoplasia in needle core biopsies have recently been reviewed. $^{72} 73$ The EUSOMA Working Group ${ }^{74}$ considered lobular neoplasia to be most frequently a coincidental finding in a core biopsy and therefore advised that multidisciplinary discussion was essential to determine management, as is advocated by others. ${ }^{75}$ Diagnostic surgical excision of lobular neoplasia has been advocated. ${ }^{76}$ A recent review of the literature revealed an upgrade of $20 \%$ for LCIS and $13 \%$ for ALH to carcinoma when excised. ${ }^{77}$ Concerns have been raised about underestimation of cancer, ${ }^{77-81}$ even with stereotactic vacuumassisted biopsy, ${ }^{79}$ and this has led to the recommendation of diagnostic surgical excision for all such lesions from some groups. ${ }^{73}$ It must be appreciated that much of the data is retrospective and that not all studies have considered radiological-pathological discordance as a factor resulting in upgrade, as found by some. ${ }^{75} 82$ What is required are large prospective studies with all factors included.

There is general agreement, although limited robust data, that pleomorphic LCIS should be subjected to therapeutic excision; in essence, treated as DCIS and therefore categorised as B5a on needle core biopsy. In one series of 12 cases diagnosed on needle core biopsy, ILC was found in 3 on subsequent excision. ${ }^{83}$ There is a need for larger studies to confirm that this does represent a more aggressive disease.

\section{Surgical excisions}

The presence and extent of lobular neoplasia in therapeutic excisions should be reported as well as its presence at margins. At present further surgery is not recommended if the invasive cancer is excised. ${ }^{68-71}$

If lobular neoplasia only is seen in a diagnostic excision biopsy and the clinical/radiologically relevant area has been excised, then no further surgery is required.

If pleomorphic LCIS is found at excision margins then it should be treated as would DCIS and further surgery undertaken

\section{Key points and recommendations}

- Due to problems in assessing the degree or extent of changes in needle core biopsies, the terms 'lobular neoplasia' or 'in situ lobular neoplasia' should be used rather than 'atypical lobular hyperplasia' and 'lobular carcinoma in situ' (LCIS). In surgical specimens, atypical lobular hyperplasia and LCIS should be distinguished and recorded.

- Lack of expression of the cell adhesion molecule E-cadherin can aid differentiation from low-grade solid DCIS.

- Pleomorphic LCIS exhibits more marked pleomorphism, necrosis and calcification. It can be differentiated from DCIS by lack of E-cadherin but should be managed as DCIS when diagnosed on needle core biopsy (B5a) and if at surgical excision margins.

- Lobular neoplasia is an indicator of increased risk of developing invasive carcinoma, which is greater for LCIS.

- There is evidence that lobular neoplasia is a non-obligate precursor lesion, based on similarities of genetic profiles with ILC and greater risk of invasion in the ipsilateral breast.

- Finding of lobular neoplasia in needle core biopsy merits multidisciplinary discussion and, for the majority, diagnostic surgical excision.

- Presence of lobular neoplasia at surgical excision margins should be recorded but does not require re-excision.

to obtain complete excision with appropriate margin of clearance.

\section{MICROMETASTASES AND ISOLATED TUMOUR CELLS (ITCS): NHSBSP COORDINATING GROUP OVERVIEW AND RECOMMENDATIONS}

Lymph node status is recognised as being a major prognostic factor for patients with breast cancer and forms part of staging systems such as the TNM (tumour, lymph node, metastases) classification system. That lymph node metastases could be 'occult' was recognised over 40 years ago, ${ }^{84}$ but their significance is still debated. The introduction of sentinel lymph node biopsy has raised further issues regarding the importance, or not, of these 'occult' metastases. These relate to their definition; how they are detected and measured; and their significance in predicting involvement of non-sentinel lymph nodes and prognosis.

\section{Definitions}

The term 'occult' metastasis has been defined as one missed by initial histological examination and identified on subsequent assessment, and also as a metastasis identified through additional evaluation of paraffin-embedded lymph node blocks. ${ }^{85}$ It has not been defined by size. Publications referring to occult metastases are therefore not necessarily comparable with regard to the size of these metastases. Some earlier studies did use $2.0 \mathrm{~mm}$ as the cut-off between micrometastasis and macrometastasis. ${ }^{86-88}$ Based on the evidence produced from these, the 5 th edition of the AJCC Cancer Staging Manual introduced the definition of micrometastasis as being $\leq 2 \mathrm{~mm}$ ( $\mathrm{pN1a}){ }^{89}$ The sixth editions of the AJCC/UICC staging manuals ${ }^{90-92}$ further defined micrometastases to be $>0.2 \mathrm{~mm}$ but not $>2.0 \mathrm{~mm}$ and introduced the term isolated tumour cells (ITC) that are $\leq 0.2 \mathrm{~mm}$ : 


\section{Micrometastases}

Isolated tumour cells (ITC
pN1mi, $>0.2 \mathrm{~mm}$, none $>2 \mathrm{~mm}$.

May have histological evidence of malignant activity (proliferation/stromal reaction) but not a requirement.

Single tumour cells or small clusters of cells no more than $0.2 \mathrm{~mm}$ in greatest dimension. Usually detected by immunohistochemistry or molecular methods, verified by H\&E section. Do not typically show proliferation/stromal reaction or penetration of vascular or lymphatic sinus walls.

pNO-no metastasis histologically. pNO $(\mathrm{i}+)$ isolated tumour cells.

Connolly, ${ }^{93}$ in discussing changes and problematic areas in the AJCC Cancer Staging Manual, identified that there could be differences in interpretation of ITCs in different situations which would result in different classification of node status. The European Working Group for Breast Screening Pathology (EWG) undertook an evaluation of low volume lymph node involvement in order to test reproducibility of these categories for distinguishing ITCs and micrometastases. ${ }^{94}$ The first evaluation of images from 50 lymph nodes showed only fair reproducibility, better for micrometastases than for ITCs. Following discussions, refinements to the definitions were proposed (box 1). The use of these refinements improved reproducibility between participants. When these criteria were used by another less specialised group to categorise the same cases, consistency was achieved

\section{Box 1 European Working Group study classification rules} (from Cserni et a ${ }^{97}$ )

- Capsular (including intravascular) lesions considered nodal, and any lesion with nodal and simultaneous extranodal involvement considered nodal, but lesions outside the node (afferent lymphatics, perinodal fat) not recorded as nodal involvement.

- Tumour cells (multiple) localised in parenchyma considered micrometastasis even if $<0.2 \mathrm{~mm}$ with no proliferation or stromal reaction.

- Tumour cells localised in vessels or sinuses: if $\leq 0.2 \mathrm{~mm}$ isolated tumour cells, if $>0.2-2 \mathrm{~mm}$ micrometastasis.

- If multiple foci, only largest should be considered.

- Single tumour cells or clusters arranged in a continuous manner or separated by $2-5$ cells should be considered and measured as one focus and characterised by largest dimension.

- Cells or clusters arranged in a discontinuous manner and dispersed homogenously in a definable part of the lymph node should be considered and measured as one focus.

- Cells, clusters or foci (as defined above) arranged in a discontinuous manner and dispersed unevenly should be considered as one if the distance between the clusters or foci is smaller than the smallest cluster or focus.

- Cells, clusters or foci (as defined above) arranged in a discontinuous manner and dispersed unevenly should be considered as distinct and multiple if the distance between the unevenly distributed tumour cells, clusters or foci is greater than the smaller cluster or focus and should be characterised by the largest cluster or focus.

- In cases of doubt, the lower category (isolated tumour cell) should be given. with the experts ${ }^{95}$ but the level of consistency was still moderate. A subsequent study to improve interobserver reproducibility was undertaken led by Turner, $^{96}$ in which six experienced breast pathologists examined digital images of small volume nodal metastases before and after studying a training programme (criteria in box 2). The EWG then applied the two interpretations of the TNM definitions and found that the Turner system had better reproducibility but it may underestimate the rate of non-sentinel node involvement. ${ }^{97}$

The evidence suggests that there are problems with using these definitions, particularly when discriminating between ITCs and micrometastases which will affect interpretation of their significance. The TNM definitions of low volume nodal metastases need to be better formulated with visual information.

\section{Detection}

The three areas that have been considered have been the extent to which lymph nodes should be examined histologically, the use of IHC and, to a lesser extent, the use of reverse transcriptase PCR to identify micrometastases and ITCs.

Histological examination of lymph nodes

How extensively to analyse a lymph node has become a question raised frequently with the increasing use of the sentinel lymph node biopsy technique.

There are differences in relation to the initial slicing of the node; the American Society of Clinical Oncology (ASCO) guidelines for sentinel lymph node biopsy in early breast cancer $^{98}$ recommend slicing through the long axis whereas NHSBSS Pathology Reporting of Breast Disease ${ }^{99}$ recommends slicing the node perpendicular to the long axis. Both advocate thin slicing and embedding all pieces. When sentinel nodes are sliced at $2 \mathrm{~mm}$ intervals and totally embedded, the probability of identifying all metastases $>2.0 \mathrm{~mm}$ is high. ${ }^{85}$ Cserni $^{100}$ used a geometrical model of sentinel lymph node histopathology and found that sections $1 \mathrm{~mm}$ apart should identify metastases $>2 \mathrm{~mm}$. To identify micrometastases, step sectioning with levels of $250 \mu \mathrm{m}$ or $200 \mu \mathrm{m}$ would be required.

A review of the literature ${ }^{101}$ on the value of using step sectioning and IHC (see below) found upstaging to be reported

\section{Box 2 Turner study classification rules (from Cserni et $\left.\left.a\right|^{97}\right)$}

- Isolated tumour cells and micrometastases are distinguished by the size of the largest tumour cell cluster, regardless of microanatomical location within or adjacent to the lymph node and regardless of the number of clusters or single cells.

- A cluster is a confluent focus of tumour cells touching other tumour cells.

- Clusters or cells separated by a single benign cell or a spatial gap are measured as separate clusters, except when fibroblastic reaction has caused the separation.

- Any lesion composed of non-cohesive cells or clusters not $>0.2 \mathrm{~mm}$ represents isolated tumour cells.

- Any lesion with largest cohesive cellular lesion $>0.2 \mathrm{~mm}$ but not $>2.0 \mathrm{~mm}$ represents micrometastasis.

- Mitotic activity is not considered.

- For borderline or indeterminate findings at the two ends of the spectrum, the lower stage category should be selected. 
after the former to range from $4.8 \%{ }^{102}$ to $30.7 \% .{ }^{103}$ However, it was difficult to assess in various studies whether this referred to macrometastasis or micrometastasis.

\section{Immunohistochemistry (IHC)}

Cytokeratin antibodies (eg, Cam5.2, MNF 116, Pan cytokeratin; AE1/AE3) have been used in many studies to aid the detection of metastases (macrometastases and micrometastases, ITCs), often in combination with step sectioning and on multiple levels in cases with negative $\mathrm{H} \& \mathrm{E}$ findings. Reviews of the literature 101104 indicate IHC results in upstaging in 2.6-19\% of cases. One study ${ }^{105}$ found IHC to detect metastases in $4 \%, 2 \%$ being micrometastases (detectable on $\mathrm{H} \& \mathrm{E}$ section on review) and $2 \%$ being ITCs, and concluded it was of limited value. Concerns about interpretation of IHC were raised by Roberts et $a l^{106}$ who found that, as tumour cell numbers decreased, the ability of pathologists to recognise them also decreased. Other concerns have been raised about IHC-only detected tumour cells in lymph nodes. ${ }^{107}$ In a review of 4066 cases of sentinel nodes positive only on IHC, there was no association with vascular invasion, tumour size, tumour type and location but there was an association with method of biopsy, the frequency increasing in relation to the degree of manipulation.

\section{Molecular analysis}

The predominant method has been reverse transcriptase PCR for a range of markers (cytokeratin 19, 20, CEA, MUC-1, maspin, mammoglobin) using either frozen sections or half the sentinel node. One of the largest series with 123 patients and 146 nodes by Manzotti et al ${ }^{108}$ had a high sensitivity but lower specificity for any marker, with a higher specificity for two of CK19, maspin or mammoglobin. Molecular analysis has recently been developed commercially for the intraoperative assessment of metastases in sentinel lymph nodes ${ }^{109-111}$ but has not been evaluated extensively.

\section{Significance}

There are two topics of importance: (1) whether micrometastases and ITCs predict the involvement of non-sentinel axillary lymph nodes and (2) the prognostic significance of micrometastases and ITCs.

\section{Predicting non-sentinel lymph node metastasis}

The aim of the sentinel node procedure is to reduce the frequency of axillary node surgery in node negative women and so reduce morbidity. Identification of sentinel node involvement is considered an indication for further axillary surgery or radiotherapy, but the question is whether such treatment is required if only a micrometastasis is present in the sentinel node. Cserni et $a l^{112}$ undertook a literature review and meta-analysis of 25 studies published up to 2003 that considered non-sentinel node metastases associated with sentinel node micrometastasis. They concluded that the risk of non-sentinel node metastasis was around 10-15\%, lower if sentinel node involvement was detected by IHC. Viale et a ${ }^{113}$ found differences in frequency of non-sentinel node metastases in relation to the size of the micrometastasis, being less if $<1 \mathrm{~mm}$. Other factors that have been found to relate to non-sentinel node metastases in the presence of sentinel node micrometastasis include tumour size, ${ }^{114-116}$ grade $^{115}$ and vascular invasion. ${ }^{116}$ Since the metaanalysis undertaken by Cserni et al, ${ }^{112}$ further publications have reported differing frequencies in the incidence of non-sentinel node metastases. In tumours $15 \mathrm{~mm}$ or less, no further involvement was found for cases with ITCs, with $12 \%$ of cases with micrometastases having non-sentinel node involvement. ${ }^{117}$ Tumour size and type were found to be factors predicting noninvolvement in the study by Houvenaeghel et al. ${ }^{118}$ Similar frequencies of involvement for cases with micrometastases have been reported in two papers from Holland $(19 \%, 20 \%),{ }^{119} 120$ although there were differences for ITCs (7\%, 13\%). In a study confined to ITC positive sentinel lymph nodes, a very low incidence of non-sentinel node metastases was found and no axillary recurrence if axillary surgery had not been performed. ${ }^{121}$

There is sufficient evidence to support the avoidance of axillary node dissection in cases with ITCs, but there is no agreement with regard to the further management of the axilla if micrometastases are identified.

\section{Prognostic significance of micrometastases and isolated tumour cells (ITCs)}

Many of the studies undertaken (reviewed by Cserni et al ${ }^{101}$ ) have considered occult metastases with only a small number commenting specifically on micrometastasis. Different combinations of $\mathrm{H} \& \mathrm{E} \pm$ step sectioning \pm IHC have been used. There is no strong evidence for a survival disadvantage. Some studies suggest that there is, but within these there are variations in relation to disease-free and overall survival and different patient groups. A study with a long follow-up that considered occult metastases found no difference in survival for patients with and without these, ${ }^{122}$ and emphasised the need for multivariate analysis in such studies. Using data taken from a cancer registry for a 25 -year period, Kuijt et al ${ }^{123}$ found on multivariate analysis that patients with micrometastases had a significantly worse survival than those without, but there was no pathological review of lymph nodes. The same applies in two studies based on data from SEER which found the prognosis for micrometastatic disease intermediate between $\mathrm{N} 0$ and $\mathrm{N}^{124}{ }^{125}$ and concluded that a prospective study is required. A re-evaluation of node negative cases with 20 -year follow-up using IHC identified $23 \%$ of cases with metastatic disease, predominantly ITCs. ${ }^{126}$ The prognosis of those with micrometastatic disease was poorer than node negative cases, which was more apparent after 10 years. Another centre examining node negative cases after 8 years of follow-up found $13 \%$ of cases with micrometastatic disease but there was no association with outcome. ${ }^{127}$

\section{USE OF BASAL/MYOEPITHELIAL MARKERS IN BREAST PATHOLOGY: NHSBSP COORDINATING GROUP OVERVIEW AND RECOMMENDATIONS}

The increasing use of needle core biopsy for non-operative diagnosis and the nature of lesions identified mammographically can result in diagnostic difficulties. Interpretation may be helped by the use of IHC to detect basal/myoepithelial markers. A recently circulated questionnaire showed that there were variations in the type and frequency of markers used diagnostically in the UK and Ireland. This paper summarises current knowledge of the various markers, discusses the diagnostic areas where they are of value and makes recommendations for a suitable diagnostic panel.

\section{Basal/myoepithelial markers}

The myoepithelial cell has traditionally been distinguished from luminal epithelial cells by the presence of smooth muscle fibres. However, many more proteins have now been identified that are expressed in myoepithelial cells and these fall into three groups (smooth muscle-related, cytokeratins and others). 


\section{Key points and recommendations}

Despite the extensive literature, there is still a lot of debate about the importance and significance of micrometastases and isolated tumour cells (ITCs), particularly with increasing use of sentinel node biopsy. This impacts on factors such as the routine pathological handling of sentinel nodes.

- If a micrometastasis is identified in a single H\&E section, levels should be cut to check whether it remains a micrometastasis or becomes a macrometastasis (pN1mi to pN1).

- Sentinel lymph nodes should be sliced at 1-2 $\mathrm{mm}$ with all pieces embedded to ensure a full face H\&E section. This is the minimum requirement. Step sectioning at $200-250 \mu \mathrm{m}$ can be undertaken but is not mandatory. It would be appropriate for centres undertaking detailed clinical studies of sentinel lymph nodes.

- There is no good evidence for the routine use of immunohistochemistry in evaluating sentinel lymph nodes; it could be of value for centres undertaking detailed clinical studies of sentinel lymph nodes.

- Definitions-AJCC/UICC amended definitions to be followed; discrimination between micrometastases and ITCs can be aided by using criteria from the European Working Group and Turner studies.

- Since there are variations in the incidence of non-sentinel node metastases in the presence of sentinel node micrometastasis, axillary surgery/radiotherapy is considered appropriate but is not indicated for ITCs.

- There is no strong evidence for an effect of micrometastases on survival.

Further data are required in several areas to assess the significance and importance of micrometastases and isolated tumour cells.

\section{Smooth muscle-related}

- Smooth muscle actin (SMA): antibodies detect actin microfilaments; good sensitivity but specificity poor since will detect myofibroblasts. ${ }^{128}$

- Smooth muscle myosin heavy chain (SMMHC): structural component of smooth muscle myosin. SM2 isoform is expressed in breast myoepithelial cells. Sensitivity and specificity are high with SMMHC being present in periductal and periacinar myoepithelial cells and not stromal myofibroblasts, ${ }^{129}$ although sensitivity reported to be slightly lower than SMA. ${ }^{128}$

- Calponin: $34 \mathrm{kD}$ polypeptide, modulates actomyosin ATPase activity. Excellent sensitivity but present in a subset of myofibroblasts. ${ }^{128} 129$

- H-caldesmon: SMA binding protein. Only detectable in myoepithelial cells of ducts but not found in myofibroblasts. ${ }^{129} 130$

\section{Cytokeratins}

- Myoepithelial cells express cytokeratins (CK) characteristic of basal layer of stratified epithelium: CK5, CK10, CK14 and CK17. ${ }^{131} 132$

- CK5/6 in normal breast can be detected in both myoepithelial and luminal epithelial cells. ${ }^{133}$

- The antibody $34 \beta 12$ recognises CKs 1, 5, 10 and 14 but is not specific for myoepithelial cells. ${ }^{134}$

\section{Other markers}

- S100: has low specificity since detectable in epithelial cells. ${ }^{135}$

- CD10 (Common Acute Lymphoblastic Leukaemia Antigen (CALLA)): endopeptide expressed in myoepithelial cells. ${ }^{136}$
Antibodies now available that work on fixed tissue; high sensitivity in normal breast. ${ }^{137}$

- P cadherin: cell adhesion molecule with high sensitivity for myoepithelial cells in normal breast, no reactivity with myofibroblasts. ${ }^{138}$

- P63-p53 homologue: differs from other markers in being nuclear ${ }^{139}$ with high sensitivity for myoepithelial cells. ${ }^{140}$

- 14-3-3б: protein associated with apoptosis and cell cycle control, present in myoepithelial cells in normal breast. ${ }^{141}$

- Maspin: serine protease inhibitor present in myoepithelial cells ${ }^{142}$ with both cytoplasmic and nuclear reactivity.

\section{Diagnostic areas}

Radial scar versus tubular carcinoma

Highly sensitive and specific markers are required due to myoepithelial cells in central parts of radial scars being attenuated, plus the presence of myofibroblasts. The requirements favour SMMHC and p63 as markers of choice. SMA and, to a lesser extent, calponin will be present in myofibroblasts.

\section{Papillary lesions}

IHC can reduce the variability in reporting of core biopsies of papillary lesions, particularly in relation to $\mathrm{B} 3$ and $\mathrm{B} 4 .{ }^{143}$ Intraduct papillomas have a complete layer of myoepithelial cells, whether detected by SMMHC, calponin, p63 and CK5/6 $6^{144}$ or SMA, p63, CD10 and CK14. ${ }^{145}$ However, findings for intracystic papillary carcinomas differ, with Collins et al ${ }^{144}$ failing to detect any myoepithelial cells and Tse et a $\left.\right|^{145}$ finding them to be scattered and discontinuous. p63 had the highest sensitivity, CK14 was also present in florid hyperplasia, SMA showed stromal staining and CD10 epithelial and stromal staining.

Hyperplasia versus atypia versus DCIS

High molecular weight basal cytokeratins are of use particularly in interpretation of core biopsies enabling a B2 rather than a B3 diagnosis. Myoepithelial cells form a useful internal positive control. Hyperplasia of usual type and hyperplasia in papillomas show reactivity for CK5/6 $133 \quad 146147$ and CK $14^{146}$ whereas atypical hyperplasia and DCIS epithelium do not.

\section{Non-invasive versus invasive carcinoma}

Myoepithelial cell markers can be of value in assessing whether or not invasion is present, but myofibroblast reactivity, discontinuity of staining of myoepithelial cells and staining of vascular smooth muscle cells can cause problems in interpretation. Discontinuous staining can occur with p63, ${ }^{140} 148$ but it has greater sensitivity and specificity. SMMHC has been found to be more sensitive than CD10 in assessing invasion ${ }^{149}$ but is in vascular smooth muscle cells. Owing to the advantages and disadvantages, it is better to use two myoepithelial markers that complement one another-for example, p63 and SMMHC or calponin.

Myoepithelial tumours

SMA, CK5/6, CK14, p63 and other markers are all suitable for analysing possible (adeno) myoepithelial tumours, both benign and malignant. ${ }^{150}$

\section{Other lesions}

Myoepithelial markers can aid differentiation of adenoid cystic carcinoma from collagenous spherulosis and cribriform carcinoma.

\section{Basal-like carcinomas}

There is increasing interest in basal-like breast carcinomas, partly due to the finding that BRCA1-related breast cancers can have these features ${ }^{151}$ and to their poorer response to anthracycline 
chemotherapy. ${ }^{152}$ There is no consensus as to the definition of basal-like, which probably reflects the view that they are a heterogeneous group of cancers. Nielsen et a ${ }^{153}$ consider them to express CK5/6, HER-1 (EGFR) and/or c-kit and lack ER and HER2. Others have used CK14 ${ }^{154}$ or P-cadherin ${ }^{155}$ as a basal marker to identify these tumours. Rakha et a ${ }^{156}$ have proposed that basallike carcinomas can be defined based on the expression of basal cytokeratins (CK5/6 and CK14) irrespective of other markers.

\section{Recommendations for a diagnostic panel}

- It is important not to rely on just one marker.

- Smooth muscle myosin heavy chain (SMMHC) or calponin are sensitive and specific cytoplasmic myoepithelial markers. Smooth muscle actin can be used but care has to be taken in interpretation in the presence of myofibroblasts.

- P63 is a sensitive and specific nuclear myoepithelial marker but staining can be discontinuous, so use of a cytoplasmic myoepithelial marker such as SMMHC or calponin as well will aid interpretation.

-When trying to identify the presence/absence of myoepithelial cells, use p63 and SMMHC/calponin.

- CK5/6 is of value in several diagnostic situations such as analysis of hyperplasias or basal-like breast cancers.

\section{OESTROGEN RECEPTOR ASSESSMENT IN DUCTAL CARCINOMA IN SITU (DCIS)}

The response of invasive breast cancer to endocrine therapy is well recognised as being related to the hormone receptor status of the tumour. ${ }^{157}$ It is therefore logical to investigate the role of hormone receptors in determining the role of endocrine therapy in the management of DCIS. However, to date, there remain issues with regard to the latter and with the assessment of hormone receptors.

\section{Evidence from clinical trials}

The value of tamoxifen in the management of DCIS has been reported in two randomised studies:

1. The NSABP B-24 trial of the use of tamoxifen and radiotherapy in DCIS showed a benefit from endocrine therapy, primarily due to a reduction of ipsilateral recurrent invasive carcinoma. ${ }^{157} 158$ The 7-year risk of local recurrence in the treated breast after lumpectomy plus radiation was reduced from $11.1 \%$ without tamoxifen to $7.7 \%$ with tamoxifen $(p=0.02)$. The risk of all breast cancer events (ipsilateral plus contralateral) was reduced from $16.9 \%$ to $10.0 \% \quad(p=0.0003)$. Allred and colleagues retrospectively reviewed 628 cases from this trial and demonstrated that the benefit was confined to those patients whose tumours were ER positive; this was defined as $10 \%$ or more cells staining. ${ }^{159}$ However, it is not clear whether there was a difference in ipsilateral and/or contralateral recurrence with regard to ER status of the primary disease process as the data are available in abstract form only. It is also not clear how the figure of $10 \%$ was reached and, in particular, whether modelling was carried out to determine a cut-off value or range that best correlated with therapeutic benefit. The review included a mixture of both locally reported ER and central assays and concern was raised about possible false negative results from laboratories using diverse nonstandardised assays. With the exception of the abstract referred to above, the study has not been published.

2. The UK/ANZ (UKCCCR) Trial ${ }^{160}$ comparing radiotherapy and tamoxifen in the treatment of DCIS showed after 53 months of follow-up a non-significant reduction in all breast events with the addition of tamoxifen but a RR reduction of $22 \%$. It should be noted that the follow-up period in the UK/ANZ trial at the time of reporting was shorter than NSABP B-24 (4.4 vs 6.9 years) and receptor status of the DCIS was not measured prospectively in this trial. In addition, a high proportion of cases were of high cytonuclear grade; a relatively high proportion are therefore likely to be ER negative which will have influenced the effect of hormone treatment in this series (S E Pinder, personal communication).

A further study, the NSABP-P1 trial of tamoxifen for the prevention of breast cancer, studied 13000 at-risk women. ${ }^{161}$ This cohort did not include patients with DCIS but illustrates the potential benefit of endocrine therapy in the prevention of breast cancer events. Invasive and non-invasive carcinomas were reduced by $50 \%$ at 69 months follow-up. There was a threefold increase in thromboembolic events, a marginal increase in cataracts and a non-significant increase in strokes.

\section{Current guidance and options}

A cut-off point for positive versus negative for ER in DCIS was set at $<5 \%$ cells staining as an entry criterion for two UK clinical trials of endocrine therapy in DCIS (IBIS II and DCIS II, the latter discontinued). The UK breast screening guidelines ${ }^{162}$ recommend the use of $<5 \%$ cells staining for DCIS and the use of the Allred score for invasive cancers. A cut-off of Allred score 3 has been used in a large study of pure DCIS examining the distribution of various different phenotypes ${ }^{162}$ and is the same as that applied to invasive breast carcinoma. ${ }^{157} 162$ It would be illogical to adopt a different scoring system from those already in use for invasive disease unless sound evidence to the contrary emerged. Furthermore, there is strong evidence that the ER status of invasive breast cancer parallels that of associated DCIS in individual cases. ${ }^{163}$ Individual practitioners benefit from familiarity with a particular scoring technique and clinical colleagues require consistency in the approach to reporting. The three scoring methods currently in use worldwide are: (1) a simple percentage of cells staining without reference to intensity; (2) the histochemical ' $\mathrm{H}$ ' score which is the sum of the percentage of cells with three levels of staining, giving a range of $0-300^{164}$; and (3) Allred scoring (replacing previous 'Quick Score') which is the sum of an intensity score of $1-3$ and the percentage of cells staining banded in a non-linear fashion using a score of $1-5$ giving a final score between 2 and $8 .{ }^{165}$

Allred scoring and the histochemical score provide similar information about receptor status as both include an assessment of intensity as well as percentage of cell nuclei staining. Simple percentage scoring gives no information about staining intensity although low proportion scores tend to go hand in hand with low intensity scoring with ER scoring, as opposed to PR immunoreactivity.

There is no evidence base to support a preference for a particular scoring technique. However, there is evidence for assessment of proportion and intensity staining in invasive breast cancer and, as such evaluation is routine practice, it would be logical to mirror this practice in the reporting of DCIS Evidence from the Sloane Project, ${ }^{166}$ a UK audit of screendetected DCIS and atypical hyperplasias of the breast, points to 
considerable confusion in this area among pathologists in their reporting practice of ER status in DCIS. A wide variation is seen between and within laboratories of the scoring method used and also of the cut-off point for positive versus negative results. In this audit, $40 \%$ of reporting laboratories used one method and the same cut-off criterion throughout, 19\% used one method but different cut-off criteria for different cases, 15\% of laboratories used two methods for different cases with equivalent cut-off points for each method while $25 \%$ of laboratories used two methods and non-equivalent cut-off points from case to case.

Because there is such uncertainty about what cut-off is therapeutically relevant (if any) in the pharmacological management of DCIS and possibly as a more general prognostic marker for this disease process, it would be sensible to record the percentage of cells staining and the average intensity in the duct profiles available and correlate this information with clinical outcomes.

\section{Patterns of ER expression in DCIS}

From the data gathered by the Sloane Project, intermediate and low-grade DCIS are almost invariably ER positive whereas high-grade DCIS is positive in $69 \%$ of cases (table 2 ).

Baqai and Shousha reviewed 60 cases of DCIS, 56 pure and four with associated microinvasion. DCIS was assessed in terms of grade, architecture and, among other things, ER positivity was defined as disease with $>10 \%$ of cells showing dark brown nuclear staining (Allred score $>4$, Histoscore $>20$ ). The grade distribution seen was 52\% high, 38\% intermediate and $10 \%$ low, which is very similar to the distribution among the Sloane Project cases. ${ }^{168}$ There was a strong association between ER negativity and high nuclear grade. The number of cases in this study was small and the cut-off point was set relatively high. It is a pity that the opportunity to model different cut-off points against grade was not taken.

Ottesen et al $^{169}$ showed in a series of 133 cases of DCIS that one-third displayed $5 \%$ or less staining for ER, the overwhelming majority of which were of large nuclear size. In this series, perhaps unusually, most cases were either strongly positive or negative.

Basal phenotype DCIS, seen in approximately $6 \%$ of high-grade lesions, is commonly negative for ER, PR and Her2. ${ }^{162} 170171$

\section{Future directions}

It is likely that the IBIS II trial will give invaluable information about the validity of setting a positive/negative cut-off point at $5 \%$ or $10 \%$ for ER. Obviously there will be limited information about the relevance of staining intensity unless Allred scores are used and these are not obligatory. The Sloane Project, given its long-term goals of prolonged follow-up of DCIS patients, will also provide information about a range of cut-off points because of the variability that has already been demonstrated in the first cohort of patients reviewed. ${ }^{167}$ Because data are not available to

Table 2 Grade of DCIS and ER status: Sloane Project data based on 1684 cases

\begin{tabular}{llllll}
\hline Grade & High (\%) & Intermediate (\%) & Low (\%) & Unknown (\%) & Total (\%) \\
\hline & $994(59)$ & $490(29)$ & $181(11)$ & $19(1)$ & 1684 \\
ER positive & $325(69)$ & $197(94)$ & $79(99)$ & 5 & $606(79)$ \\
ER negative & $148(31)$ & $12(6)$ & $1(1)$ & & $161(21)$ \\
Unknown & 521 & 281 & 101 & 14 & \\
\hline
\end{tabular}

DCIS, ductal carcinoma in situ; ER, oestrogen receptor.

\section{Key points and recommendations}

- $>80 \%$ of DCIS is ER positive and there is a body of evidence indicating a therapeutic benefit for endocrine treatment in selected ER positive patients.

- Previously a cut-off point of $5 \%$ of cells staining has been recommended to define positive and negative. It is recommended that both proportion of cells staining and intensity should be recorded.

\section{Take-home messages}

- Columnar cell lesions may show a spectrum of abnormalities from simple metaplasia to ductal carcinoma in situ.

- Lobular neoplasia or in situ lobular neoplasia are the preferred terms for core needle biopsy reports whereas the terms atypical lobular hyperplasia or lobular carcinoma in situ should be specified in excisions.

- Metastatic tumour clusters in lymph nodes $<0.2 \mathrm{~mm}$ are designated isolated tumour cells. Discontinuous clusters should be measured as one focus if in a definable part of a lymph node. Unevenly dispersed clustered should be characterised by the largest cluster.

- When using basal/myoepithelial markers do not rely on a single marker. There is often mismatch between individual marker's staining profiles.

- ER scoring for DCIS should follow practice in invasive disease recording both proportion and intensity of cells staining using, for example, a Histoscore or Allred type system.

give guidance on the clinical relevance of different proportion and intensity scores, it is recommended as a minimum to record both when reporting the hormone receptor status of DCIS. This will enable Histoscores and/or Allred scores to be derived without loss of the original scoring information.

There remains considerable scope for modelling ER cut-off points in DCIS against clinical outcomes in large cohorts of patients but, until such time as that is possible, it seems reasonable to apply the limited evidence available at the present time and use the currently accepted cut-off points to guide the endocrine management of patients with DCIS as for reporting ER status in invasive breast cancer. ${ }^{162}$

Acknowledgements The authors acknowledge the members of the UK National Coordinating Committee for Breast Pathology.

Contributors These are working documents aimed to established early guidance on emerging areas of diagnostic breast pathology.

Competing interests None.

Provenance and peer review Commissioned; internally peer reviewed.

\section{REFERENCES}

1. Fraser JL, Raza S, Chorny K, et al. Columnar alteration with prominent apical snouts and secretions: a spectrum of changes frequently present in breast biopsies performed for microcalcifications. Am J Surg Pathol 1998;22:1521-7.

2. Ishihara A, Kobayashi TK. Infarcted intraductal papilloma of the breast: cytologic features with stage of infarction. Diagn Cytopathol 2006;34:373-6.

3. Cameselle-Teijeiro J, Abdulkader I, Barreiro-Morandeira F, et al. Breast tumor resembling the tall cell variant of papillary thyroid carcinoma: a case report. Int J Surg Pathol 2006;14:79-84. 
4. Tremblay G, Deschenes J, Alpert L, et al. Overexpression of estrogen receptors in columnar cell change and in unfolding breast lobules. Breast $J$ 2005;11:326-32.

5. Vincent-Salomon A. [Columnar lesions: a frequent diagnosis in breast pathology!] (In French). Ann Pathol 2003;23:593-6.

6. Schnitt SJ, Vincent-Salomon A. Columnar cell lesions of the breast. Adv Anat Pathol 2003;10:113-24.

7. Tavassoli FA, Devilee P. Pathology and Genetics of Tumours of the Breast and Female Genital Tract. Lyon: IARC Press, 2003.

8. Page D, Anderson T. Diagnostic Histopathology of the Breast. Edinburgh: Churchill Livingstone, 1987.

9. Rosen PP. Columnar cell hyperplasia is associated with lobular carcinoma in situ and tubular carcinoma. Am J Surg Pathol 1999;23:1561.

10. Rosen PP. Rosen's Breast Pathology. 2nd edn. Philadelphia: Lippincott Williams \& Wilkins, 2001

11. Foote FW, Stewart FW. Comparative studies of cancerous versus noncancerous breast I. Basic morphologic characteristics. Ann Surg 1945;121:6-53.

12. Goldstein NS, O'Malley BA. Cancerization of small ectatic ducts of the breast by ductal carcinoma in situ cells with apocrine snouts: a lesion associated with tubular carcinoma. Am J Clin Pathol 1997;107:561-6.

13. Sasse F. Über Cysten und cystiche Tumoren der Mamma. Arch Klin Chir 1897:54:1-54.

14. Schimmelbusch G. Das Cystadenom der Mamma. Arch Klin Chir 1892;44:117-34.

15. Oyama T, Maluf $H$, Koerner F. Atypical cystic lobules: an early stage in the formation of low-grade ductal carcinoma in situ. Virchows Arch 1999;435:413-21.

16. Bonser G, Dossett JA, Jull JW. Human and Experimental Breast Cancer. London: Pitman Medical, 1961.

17. Wellings SR, Jensen HM, Marcum RG. Atlas of subgross pathology of the human breast with special reference to possible cancerous lesions. J Natl Cancer Inst 1975:55:231-73

18. Kusama R, Fujimori M, Matsuyama I, et al. Clinicopathological characteristics of atypical cystic duct (ACD) of the breast: assessment of $A C D$ as a precancerous lesion. Pathol Int 2000;50:793-800

19. Moinfar F, Man YG, Bratthauer GL, et al. Genetic abnormalities in mammary ductal intraepithelial neoplasia- at type ("clinging ductal carcinoma in situ"): a simulator of normal mammary epithelium. Cancer 2000;88:2072-81.

20. Allred DC, Mohsin SK. Biological features of premalignant disease in the human breast. J Mammary Gland Biol Neoplasia 2000;5:351-64.

21. Viale G. Histopathology of primary breast cancer 2005. Breast 2005;14:487-92.

22. Brogi E, Oyama T, Koerner FC. Atypical cystic lobules in patients with lobular neoplasia. Int J Surg Pathol 2001;9:201-6.

23. McLaren BK, Gobbi H, Schuyler PA, et al. Immunohistochemical expression of estrogen receptor in enlarged lobular units with columnar alteration in benign breast biopsies: a nested case-control study. Am J Surg Pathol 2005:29:105-8.

24. Bratthauer GL, Tavassoli FA. Assessment of lesions coexisting with various grades of ductal intraepithelial neoplasia of the breast. Virchows Arch 2004; $444: 340-4$

25. The Mammary Gland: Development, Regulation, and Function. New York, NY: Plenum Press, 1987

26. Van Poznak C, Cross SS, Saggese M, et al. Expression of osteoprotegerin (OPG), TNF related apoptosis inducing ligand (TRAIL), and receptor activator of nuclear factor kappaB ligand (RANKL) in human breast tumours. J Clin Pathol 2006;59:56-63.

27. Otterbach F, Bankfalvi A, Bergner S, et al. Cytokeratin 5/6 immunohistochemistry assists the differential diagnosis of atypical proliferations of the breast. Histopathology 2000;37:232-40.

28. Dabbs DJ, Carter G, Fudge $\mathrm{M}$, et al. Molecular alterations in columnar cell lesions of the breast. Mod Pathol 2006;19:344-9.

29. Eusebi V, Feudale E, Foschini MP, et al. Long-term follow-up of in situ carcinoma of the breast. Semin Diagn Pathol 1994;11:223-35.

30. Simpson PT, Gale T, Reis-Filho JS, et al. Columnar cell lesions of the breast: the missing link in breast cancer progression? A morphological and molecular analysis. Am J Surg Pathol 2005;29:734-46.

31. Tan PH, Ho BC, Selvarajan S, et al. Pathological diagnosis of columnar cell lesions of the breast: are there issues of reproducibility? J Clin Pathol 2005; 58:705-9.

32. O'Malley FP, Mohsin SK, Badve S, et al. Interobserver reproducibility in the diagnosis of at epithelial atypia of the breast. Mod Pathol 2006;19:172-9.

33. Foote FW Jr, Stewart FW. Lobular carcinoma in situ. A rare form of mammary cancer. Am J Pathol 1941;17:491-6.

34. Haagensen CD, Lane N, Lattes $\mathrm{R}$, et al. Lobular neoplasia (so-called lobular carcinoma in situ) of the breast. Cancer 1978:42:737-69.

35. Wheeler JE, Enterline HT, Roseman JM, et al. Lobular carcinoma in situ of the breast. Long-term followup. Cancer 1974:34:554-63.

36. Andersen JA. Lobular carcinoma in situ. A long-term follow-up in 52 cases. Acta Pathol Microbiol Scand A 1974;82:519-33.

37. Bratthauer GL, Tavassoli FA. Lobular intraepithelial neoplasia: previously unexplored aspects assessed in 775 cases and their clinical implications. Virchows Arch 2002;440:134-8.

38. Lobular neoplasia. In: Tavassoli FA, Devilee P, eds. Pathology and Genetics of Tumours of the Breast and Female Genital Organs. World Health Organization Classification of Tumours. Lyon: IARC Press, 2003:60-2.
39. Eusebi V, Magalhaes F, Azzopardi JG. Pleomorphic lobular carcinoma of the breast: an aggressive tumor showing apocrine differentiation. Hum Pathol 1992;23:655-62.

40. Sneige N, Want J, Baker BA, et al. Clinical, histopathologic and biologic features of pleomorphic lobular (ductal-lobular) carcinoma in situ of the breast: a report of 24 cases. Mod Pathol 2002;15:1044-50.

41. Reis-Filho JS, Simpson PT, Jones C, et al. Pleomorphic lobular carcinoma of the breast: role of comprehensive molecular pathology in characterization of an entity. J Pathol 2005;207:1-13.

42. Fadare 0, Dadmanesh F, Alvarado-Cabrero I, et al. Lobular intraepithelial neoplasia [lobular carcinoma in situ] with comedo-type necrosis. Am J Surg Pathol 2006:30:1445-53.

43. Koerner $\mathbf{F}$, Maluf H. Uncommon morphologic patterns of lobular neoplasia. Ann Diagn Pathol 1999;3:249-59.

44. Page DL, Kidd TE Jr, Dupont WD, et al. Lobular neoplasia of the breast: higher risk for subsequent invasive cancer predicted by more extensive disease. Hum Pathol 1991:22:1232-9.

45. De Leuuw WJ, Berx G, Vos CB, et al. Simultaneous loss of E-cadherin and catenins in invasive lobular breast cancer and lobular carcinoma in situ. J Pathol 1997: 183:404-11.

46. Vos CB, Cleton-Jansen AM, Berx G, et al. E-cadherin inactivation in lobular carcinoma in situ of the breast: an early event in tumorigenesis. Br J Cancer 1997:76:1131-3.

47. Simpson PT, Gale T, Fulford LG, et al. The diagnosis and management of preinvasive breast disease: pathology of atypical lobular hyperplasia and lobular carcinoma in situ. Breast Cancer Res 2003;5:258-62.

48. Maluf HM. Differential diagnosis of solid carcinoma in situ. Semin Diagn Pathol 2001:25:237-44.

49. Maluf HM, Swanson PE, Koerner FC. Solid low-grade in situ carcinoma of the breast: role of associated lesions and E-cadherin in differential diagnosis. Am J Surg Pathol 2001:25:237-44.

50. Jacobs TW, Pliss N, Kouria G, et al. Carcinomas in situ of the breast with indeterminable features: role of E-cadherin staining in categorization. Am J Surg Pathol 2001:25:229-36.

51. Dabbs DJ, Bhargava R, Chivukula M. Lobular versus ductal breast neoplasms. The diagnostic utility of p120 catenin. Am J Surg Pathol 2007;31:427-37.

52. Bratthauer GL, Moinfar F, Stamatakos MD, et al. Combined E-cadherin and high molecular weight cytokeratin immuno-profile differentiates lobular, ductal and hybrid mammary intraepithelial neoplasias. Hum Pathol 2002:33:620-7.

53. Bratthauer GL, Miettinen M, Tavassoli FA. Cytokeratin immunoreactivity in lobular intraepithelial neoplasia. J Histochem Cytochem 2003;51:1527-31.

54. Droufakou S, Deshmane V, Roylance R, et al. Multiple ways of silencing E-cadherin gene expression in lobular carcinoma of the breast. Int J Cancer 2001;92:404-8.

55. Sarrio D, Moreno-Bueno G, Hardisson D, et al. Epigenetic and genetic alterations of $\mathrm{APC}$ and $\mathrm{CDH} 1$ genes in lobular breast cancer: relationships with abnormal E-cadherin and catenin expression and microsatellite instability. Int $J$ Cancer 2003;106:208-15

56. Mastracci TL, Tjan S, Bane AL, et al. E-cadherin alterations in atypical lobular hyperplasia and lobular carcinoma in situ of the breast. Mod Pathol 2005: 18:741-51.

57. Lu YJ, Osin P, Lakhani S, et al. Comparative genomic hybridization analysis of lobular carcinoma in situ and atypical lobular hyperplasia and potential roles for gains and losses of genetic material in breast neoplasia. Cancer Res 1998:58:4721-7.

58. Shelley Hwang E, Nyante SJ, Yi Chen Y, et al. Clonality of lobular carcinoma in situ and synchronous invasive lobular carcinoma. Cancer 2004;100:2562-72.

59. Morandi L, Marucci G, Foschini MP, et al. Genetic similarities and differences between lobular in situ neoplasia (LN) and invasive lobular carcinoma of the breast. Virchows Arch 2006;449:14-23.

60. Page DL, Dupont WD, Rogers LW, et al. Atypical hyperplastic lesions of the female breast. A long term follow-up study. Cancer 1985;55:2698-708.

61. Page DL, Dupont WD, Rogers LW. Ductal involvement by cells of atypical lobular hyperplasia in the breast: a long term follow-up study of cancer risk. Hum Pathol 1988:19:201-7

62. Page DL, Schuyler PA, Dupont WA, et al. Atypical lobular hyperplasia as a unilateral predictor of breast cancer risk: a retrospective cohort study. Lancet 2003:361:125-9.

63. Ottesen GL, Graversen HP, Blichert-Toft M, et al. Lobular carcinoma in situ of the female breast. Short term results of a prospective nationwide study. The Danish Breast Cancer Cooperative Group. Am J Surg Pathol 1993;17:14-21.

64. Chuba PJ, Hamre MR, Yap J, et al. Bilateral risk for subsequent breast cancer after lobular carcinoma-in-situ: analysis of surveillance, epidemiology and end results data. J Clin Oncol 2005;23:5534-41.

65. Rosen PP, Kosloff C, Lieberman PH, et al. Lobular carcinoma in situ of the breast: detailed analysis of 99 patients with average follow-up of 24 years. Am J Surg Pathol 1978;2:225-51.

66. Collins LC, Baer JH, Tamimi RM, et al. Magnitude and laterality of breast cancer risk according to histologic type of atypical hyperplasia. Cancer 2007:109:180-7.

67. Li CI, Malone KE, Saltzman BS, et al. Risk of invasive breast carcinoma among women diagnosed with ductal carcinoma in situ and lobular carcinoma in situ, 1988-2001. Cancer 2006;106:2104-12. 
68. Abner AL, Connolly JL, Recht $\mathrm{A}$, et al. The relation between the presence and extent of lobular carcinoma in situ and the risk of local recurrence for patients with infiltrating carcinoma of the breast treated with conservative surgery and radiation therapy. Cancer 2000;88:1072-7.

69. Fisher ER, Land SR, Fisher B, et al. Pathologic findings from the National Surgical Adjuvant Breast and Bowel Project. Twelve-year observations concerning lobular carcinoma in situ. Cancer 2004;100:238-44.

70. Ben-David MA, Kleer CG, Paramagui C, et al. Is lobular carcinoma in situ as a component of breast carcinoma a risk factor for local failure after breast-conserving therapy? Results of a matched pair analysis. Cancer 2006;106:28-34

71. Adepoju LJ, Symmans WF, Babiera GV, et al. Impact of concurrent proliferative high-risk lesions on the risk of ipsilateral breast carcinoma recurrence and contralateral breast carcinoma development in patients with ductal carcinoma in situ treated with breast-conserving therapy. Cancer 2006:106:42-50.

72. Pinder SE, Provenzano E, Reis-Filho JS. Lobular in situ hyperplasia and columna cell lesions: diagnosis in breast core biopsies and implications for management. Pathology 2007;39:208-16.

73. Reis-Filho JS, Pinder SE. Non-operative breast pathology: lobular neoplasia. J Clin Pathol 2007:60:1321-7.

74. Lakhani SR, Audretsch W, Cleton-Jensen AM, et al. The management of lobular carcinoma in situ (LCIS). Is LCIS the same as ductal carcinoma in situ (DCIS)? Eur J Cancer 2006:42:2205-11.

75. Menon S, Porter GJ, Evans AJ, et al. The significance of lobular neoplasia on needle core biopsy of the breast. Virchows Arch 2008:452:473-9.

76. O'Driscoll D, Britton P, Bobrow L, et al. Lobular carcinoma in situ diagnosed on core biopsy - what is the clinical significance? Clin Radiol 2001;56:216-20

77. Cangiarella J, Guth A, Axelrod D, et al. Is surgical excision necessary for the management of atypical lobular hyperplasia and lobular carcinoma in situ diagnosed on core needle biopsy? A report of 38 cases and review of the literature. Arch Pathol Lab Med 2008:132:979-83.

78. Elsheikh TM, Silverman JF. Follow-up surgical excision is indicated when breast core needle biopsies show atypical lobular hyperplasia or lobular carcinoma in situ. Am J Surg Pathol 2005:29:534-43.

79. Mahoney MC, Robinson-Smith TM, Shaughnessy EA. Lobular neoplasia at 11- gauge vacuum-assisted stereotactic biopsy: correlation with surgical excision biopsy and mammographic follow-up. AJR Am J Roentgenol 2006;187:949-54.

80. Houssami N, Caitto S, Bilous $\mathrm{M}$, et al. Borderline breast core needle histology: predictive values for malignancy in lesions of uncertain malignant potential (B3). Br J Cancer 2007:96:1253-7.

81. Londero V, Zuiani C, Linda A, et al. Lobular neoplasia: core needle breast biopsy underestimation of malignancy in relation to radiologic and pathologic features. Breast 2008;17:623-30.

82. Hwang H, Barke LD, Mendelson EB, et al. Atypical lobular hyperplasia and classic lobular carcinoma in situ in core biopsy specimens; routine excision is no necessary. Mod Pathol 2008;21:1208-16.

83. Chivukula M, Haynick DM, Brufsky A, et al. Pleomorphic lobular carcinoma in situ (PLCIS) on breast core needle biopsies: clinical significance and immunoprofile. Am J Surg Pathol 2008:32:1721-6.

84. Pickren JW. Significance of occult metastases. A study of breast cancer. Cancer 1961;14:1266-71.

85. Weaver DL. Sentinel lymph nodes and breast carcinoma. Which micrometastases are significant? Am J Surg Pathol 2003;27:842-5.

86. Huvos AG, Hutter R, Berg JW. Significance of axillary macrometastases and micrometastases in mammary carcinoma. Ann Surg 1971:173:44-6.

87. Fisher ER, Palekar R, Rockette $\mathrm{H}$, et al. Pathological findings for the National Surgical Adjuvant Breast and Bowel Project (Protocol \# 4). Significance of axillary nodal micro- and macrometastases. Cancer 1978:42:3032-8.

88. Rosen PP, Saigo P, Braun DW Jr, et al. Occult axillary lymph node metastases in breast cancer: prognostic significance of tumor size. Ann Surg 1981;194:585-91.

89. Fleming ID, Cooper JS, Henson DE, et al, eds. AJCC Cancer Staging Manual. 5th edn. Philadelphia: Lippincott-Raven, 1997

90. Greene FL, Page DL, Fleming ID, et al. AJCC Cancer Staging Manual. 6th edn. New York: Springer-Verlag, 2002

91. Sobin LH, Wittekind C, eds. UICC TNM Classification of Malignant Tumours. 6th edn. New York: John Wiley \& Sons, Inc, 2002

92. Singletary SE, Greene FL, Sobin LH. Classification of isolated tumor cells: clarification of the $6^{\text {th }}$ edition of the American Joint Committee on Cancer Staging manual. Cancer 2003;98:2740-1.

93. Connolly JL. Changes and problematic areas in interpretation of the AJCC Cancer Staging Manual, 6th edition, for breast cancer. Arch Pathol Lab Med 2006;130:287-91.

94. Cserni G, Bianchi S, Boecker W, et al; for the European Working Group for Breast Screening Pathology. Improving the reproducibility of diagnosing micrometastases and isolated tumor cells. Cancer 2005;103:358-67.

95. Cserni G, Sapino A, Decker T. Discriminating between micrometastases and isolated tumor cells in a regional and institutional setting. Breast 2006;15:347-54

96. Turner RR, Weaver DL, Cserni G, et al. Nodal stage classification for breast carcinoma: improving interobserver reproducibility through standardized histologic criteria and image-based training. J Clin Oncol 2008;26:258-63.
97. Cserni G, Bianchi S, Vezzosi V, et al. Variations in sentinel node isolated tumour cells/micrometastasis and non-sentinel node involvement rates according to different interpretations of the TNM definitions. Eur J Cancer 2008;44:2185-91.

98. Lyman GH, Guiliano AE, Somerfield MK, et al. American Society of Clinical Oncology guideline recommendations for sentinel lymph node biopsy in early stage breast cancer. J Clin Oncol 2005:23:7703-20.

99. Ellis I0, Pinder SE, Bobrow L, et al. Pathology reporting of Breast Disease. Sheffield, UK: NHS cancer Screening Programmes, 2005.

100. Cserni G. A model for determining the optimum histology of sentinel lymph nodes in breast cancer. J Clin Pathol 2004;57:467-71.

101. Cserni G, Amendoeira I, Apostolikas N, et al; European Working Group for Breast Screening Pathology. Pathological work-up of sentinel lymph nodes in breast cancer. Review of current data to be considered for the formulation of guidelines. Eur $\mathrm{J}$ Cancer 2003;39:1654-67.

102. Turner RR, Ollila D, Stern S, et al. Optimal histopathologic examination of the sentinel lymph node for breast carcinoma staging. Am J Surg Pathol 1999;23:263-7.

103. Dowlatshahi K, Fan M, Anderson JM, et al. Occult metastases in sentinel nodes of 200 patients with operable breast cancer. Ann Surg Oncol 2001;8:675-81.

104. Cserni G. Complete sectioning of axillary sentinel nodes in patients with breast cancer. Analysis of two different step sectioning and immunohistochemistry protocols in 246 patients. J Clin Pathol 2002:55:926-31.

105. Klevesath MB, Bobrow LG, Pinder SE, et al. The value of immuno-histochemistry in sentinel lymph node histopathology in breast cancer. Br J Cancer 2005:92:2201-5.

106. Roberts CA, Beitsch PD, Litz CE, et al. Interpretative disparity among pathologists in breast cancer sentinel lymph node evaluation. Am J Surg 2003:186:324-9.

107. Moore KH, Thaler HT, Tan LK, et al. Immunohistochemically detected tumor cells in the sentinel lymph nodes of patients with breast carcinoma. Biologic metastasis or procedural artefact? Cancer 2004; 100:929-34

108. Manzotti M, Dell Orto P, Maisonneuve P, et al. Reverse transcriptase polymerase chain reaction assay for multiple mRNA markers in the detection of breast cancer metastases in sentinel lymph nodes. Int J Cancer 2001;95:307-12.

109. Viale G, Dell'Orto P, Biasi DO, et al. Comparative evaluation of an extensive histopathologic examination and a real-time reverse transcriptase-polymerase chain reaction assay for mammoglobin and cytokeratin 19 on axillary sentinel lymph nodes of breast carcinoma patients. Ann Surg 2008;247:136-42.

110. Martin Martinez MD, Veys I, Majjaj S, et al. Clinical validation of a molecular assay for intra-operative detection of metastases in breast sentinel lymph nodes. Eur J Surg Oncol 2009:35:387-92.

111. Mansel RE, Goyal A, Douglas-Jones A, et al. Detection of breast cancer metastasis in sentinel lymph nodes using intra-operative real time GeneSearch ${ }^{\mathrm{TM}}$ BLN assay in the operating room: results of the Cardiff study. Breast Cancer Res Treat 2009;115:595-600.

112. Cserni G, Gregori D, Merletti F, et al. Meta-analysis of non-sentinel node metastases associated with micrometastatic sentinel nodes in breast cancer. $\mathrm{Br} \mathrm{J}$ Surg 2004;91:1245-52.

113. Viale G, Maiorano E, Mazzarol G, et al. Histologic detection and clinical implications of micrometastases in axillary sentinel lymph nodes for patients with breast carcinoma. Cancer 2001;92:1378-84.

114. den Bakker MA, van Weeszenberg A, de Kanter AY, et al. Non-sentinel lymph node involvement in patients with breast cancer and sentinel node micrometastasis; too early to abandon axillary clearance. J Clin Pathol 2002;55:932-5.

115. Dabbs DJ, Fung D, Landsittel D, et al. Sentinel lymph node micrometastasis as a predictor of axillary tumor burden. Breast J 2004;10:101-5.

116. Carcoforo $\mathbf{P}$, Bergossi L, Basaglia E, et al. Prognostic and therapeutic impact of sentinel node micrometastasis in patients with invasive breast cancer. Tumori 2002;88:54-5.

117. Cserni G, Bianchi S, Vezzosi V, et al. Sentinel lymph node biopsy in staging small (upto $15 \mathrm{~mm}$ ) breast carcinomas. Results from a European multi-institutional study. Pathol Oncol Res 2007;13:5-14.

118. Houvenaeghel G, Nos $\mathrm{C}$, Mignotte $\mathrm{H}$, et al. Micrometastases in sentinel lymph node in a multicentric study: predictive factors of nonsentinel lymph node involvement: Groupe de Chirurgiens de la Federation des Centres de Lutte Contre le Cancer. J Clin Oncol 2006:24:1814-22.

119. Van Rijk MC, Peterse JL, Nieweg OE, et al. Additional axillary metastases and stage migration in breast cancer patients with micrometastases or submicrometastases in sentinel lymph nodes. Cancer 2006;107:467-71.

120. Van Deurzen CH, Van HR, Hobbelink MG, et al. Predictive value of tumor load in breast cancer sentinel lymph nodes for second echelon lymph node metastases. Cell Oncol 2007;29:497-505.

121. Calhoun KE, Hansen NM, Turner RR, et al. Non-sentinel node metastases in breas cancer patients with isolated tumor cells in the sentinel node: implications for completion axillary node dissection. Am J Surg 2005;190:588-91.

122. Millis RR, Springall R, Lee AH, et al. Occult lymph node metastases are of no prognostic significance in breast cancer. Br J Cancer 2002;86:396-41.

123. Kuijt GP, Voogd AC, van de Poll-Frause LV, et al. The prognostic significance of axillary lymph node micrometastases in breast cancer patients. Eur J Surg Oncol 2005:31:500-5.

124. Maibenco DC, Dombi GW, Kau TY, et al. Significance of micrometastases on the survival of women with T1 breast cancer. Cancer 2006:107:1234-9.

125. Chen SL, Hoehne FM, Giuliano AE. The prognostic significance of micrometastases in breast cancer: a SEER population-based analysis. Ann Surg Oncol 2007;15:3378-84. 
126. Tan LK, Giri D, Hummer AJ, et al. Occult axillary node metastases in breast cancer are prognostically significant: results in 368 node-negative patients with 20-year follow-up. J Clin Oncol 2008;26:1803-9.

127. Kahn HJ, Hanna WM, Chapman JA, et al. Biological significance of occult micrometastases in histologically negative axillary lymph nodes in breast cancer patients using the recent American Joint Committee on Cancer staging system. Breast J 2006;12:294-301.

128. Yaziji H, Gown AM, Sneige N. Detection of stromal invasion in breast cancer: the myoepithelial markers. Adv Anat Pathol 2000:7:100-9.

129. Foschini MP, Scarpellini F, Gown AM, et al. Differential expression of moyepithelial markers in salivary, sweat and mammary glands. Int J Surg Pathol 2000;8:29-37.

130. Lazard D, Sastre X, Frid MG, et al. Expression of smooth muscle specific proteins in myoepithelium and stromal myofibroblasts of normal and malignant human breast tissue. Proc Natl Acad Sci U S A 1993;90:9990-1003.

131. Dairkee SH, Blayney C, Smith HS, et al. Monoclonal antibody that defines human myoepithelium. Proc Natl Acad Sci U S A 1985;82:7409-13.

132. Nagle RB, Bocker W, David JR, et al. Characterization of breast carcinomas by two monoclonal antibodies distinguishing myoepithelial from luminal epithelial cells. J Histochem Cytochem 1986;34:869-81.

133. Otterbach F, Bankfalvi A, Bergher $\mathrm{S}$, et al. Cytokeratin $5 / 6$ immunohistochemistry assists the differential diagnosis of atypical proliferations of the breast. Histopathology 2000;37:232-40.

134. Joshi MG, Lee AK, Pedersen CA, et al. The role of immunocytochemical markers in the differential diagnosis of proliferative and neoplastic lesions of the breast. Mod Pathol 1996;9:57-62.

135. Dwarakanath $\mathbf{S}$, Lee AK, Delellis RA, et al. S100 protein positivity in breast carcinomas: a potential pitfall in diagnostic immunohistochemistry. Hum Pathol 1987; 18:1144-8

136. Gusterson BA, Monaghan P, Manhendran R, et al. Identification of myoepithelial cells in human and rat breasts by anti-common acute lymphoblastic leukaemia antigen antibody A12. J Natl Cancer Inst 1986:77:343-9.

137. Moritani S, Kushima R, Sugihara H, et al. Availability of CD10 immunohistochemistry as a marker of breast myoepithelial cells on paraffin sections. Mod Pathol 2002;15:397-405.

138. Kovacs A, Walker RA. P-cadherin as a marker in the differential diagnosis of breast lesions. J Clin Pathol 2003:546:139-41.

139. Barbareschi M, Pecciarini L, Cangi MG, et al. p63, a p53 homologue, is a selective nuclear marker of myoepithelial cells of the human breast. Am J Surg Pathol 2001:25:1056-60.

140. Werling RW, Hwang $\mathrm{H}$, Yaziji $\mathrm{H}$, et al. Immunohistochemical distinction of invasive from non-invasive breast lesions. A comparative study of p63 versus calponin and smooth muscle myosin heavy chain. Am J Surg Pathol 2003:27:82-90.

141. Simpson PT, Gale T, Reis-Filho JS, et al. Distribution and significance of 14-3-3 sigma, a novel moyepithelial marker, in normal, benign and malignant tissue. J Pathol 2004:202:274-85.

142. Reis-Filho JS, Milanezi F, Silva P, et al. Maspin expression in myoepithelial tumours of the breast. Pathol Res Pract 2002;197:817-21.

143. Douglas-Jones A, Shah V, Morgan J, et al. Observer variability in the histopathological reporting of core biopsies of papillary breast lesions is reduced by the use of immunohistochemistry for CK5/6, calponin and p63. Histopathology 2005; $47: 202-8$

144. Collins LC, Carlo VP, Hwang H, et al. Intracystic papillary carcinomas of the breast: a re-evaluation using a panel of myoepithelial cell markers. Am J Surg Pathol 2006;30:1002-7.

145. Tse GM, Tan PH, Lui PC, et al. The role of immunohistochemistry for smooth muscle actin, p63, CD10 and CK14 in the differential diagnosis of papillary lesions of the breast. J Clin Pathol 2007;60:315-20.

146. Tan PH, Aw MY, Yip G, et al. Cytokeratins in papillary lesions of the breast. Is there a role in distinguishing intraductal papilloma from papillary ductal carcinoma in situ. Am J Surg Pathol 2005;29:625-32.

147. Rabban JT, Koerner FC, Lerwill MF. Solid papillary ductal carcinoma in situ versus usual ductal hyperplasia in the breast: a potentially difficult distinction resolved by cytokeratin 5/6. Hum Pathol 2006;37:787-93.

148. Ribeiro-Silva A, Zamzelli Ramalho LN, Garcia SB, et al. Is p63 reliable in detecting microinvasion in ductal carcinoma in situ of the breast. Pathol Oncol Res 2003:9:20-3
149. Kalof AN, Tam D, Beatty B, et al. Immunostaining patterns of myoepithelial cells in breast lesions: a comparison of CD10 and smooth muscle myosin heavy chain. $J$ Clin Pathol 2004;57:625-9.

150. Hungermann D, Buerger $\mathrm{H}$, Oehlschregel $\mathrm{C}$, et al. Adenomyoepithelial tumours and myoepithelial carcinomas of the breast - a spectrum of monophasic and biphasic tumours dominated by immature myoepithelial cells. BMC Cancer 2005;5:92-102

151. Turner NC, Reis-Filho JS. Basal-like breast cancer and the BRCA1 phenotype. Oncogene 2006;25:5846-53.

152. Banerjee S, Reis-Filho JS, Ashley S, et al. Basal-like breast carcinomas: clinical outcome and response to chemotherapy. J Clin Pathol 2006;59:729-35.

153. Neilsen T0, Hsu FD, Jensen K, et al. Immunohistochemical and clinical characterization of the basal-like subtype of invasive breast carcinoma. Clin Cancer Res 2004; 10:5367-74.

154. Fulford LG, Easton DP, Reis-Filho JS, et al. Specific morphological features predictive for the basal phenotype in grade 3 invasive ductal carcinoma of breast. Histopathology 2006:49:22-34.

155. Arnes JB, Brunet JS, Stefannson I, et al. Placental cadherin and the basal epithelial phenotype of BRCA-1 related breast cancer. Clin Cancer Res 2005:11:4003-11.

156. Rakha EA, El-Sayed ME, Green AR, et al. Breast carcinoma with basal differentiation: a proposal for pathology definition based on basal cytokeratin expression. Histopathology 2007:50:434-8.

157. Fisher B, Dignam J, Wolmark N, et al. Tamoxifen in treatment of intraductal breas cancer: National Surgical Adjuvant Breast and Bowel Project B-24 randomised controlled trial. Lancet 1999;353:1993-2000.

158. Fisher B, Land S, Mamounas E, et al. Prevention of invasive breast cancer in women with ductal carcinoma in situ: an update of the National Surgical Adjuvant Breast and Bowel Project experience. Semin Oncol 2001;28:400-18.

159. Allred DC, Bryant J, Land S, et al. Estrogen receptor expression as a predictive marker of the effectiveness of tamoxifen in the treatment of DCIS: findings from the NSABP Protocol B-24 (abstract 30). Br Cancer Res Tr 2002;76:S36.

160. Houghton J, George WD, Cusick J, et al. Radiotherapy and tamoxifen in women with completely excised ductal carcinoma in situ of the breast in the UK, Australia and New Zealand: randomised controlled trial. Lancet 2003;362:95-192.

161. Fisher B, Constantino JP, Wickerham L, et al. Tamoxifen for prevention of breas cancer: report of the National Surgical Adjuvant Breast and Bowel Project P-1 study. J Natl Cancer Inst 1998;90:1371-88.

162. Anon. Pathology Reporting of Breast Disease. NHS Breast Screening Programme Publication No 58. NHS Cancer Screening Programmes and the Royal College of Pathologists. 2005:87

163. Livasy CA, Perou CM, Karaca G, et al. Identification of a basal-like subtype of breast ductal carcinoma in situ. Hum Pathol 2007;38:197-204.

164. Leong AS, Sormunen RT, Vinyuvat S, et al. Biologic markers in ductal carcinoma in situ and concurrent infiltrating carcinoma. A comparison of eight contemporary grading systems. Am J Clin Pathol 2001;115:709-18.

165. McCarty KS Jr, Szabo E, Flowers JL, et al. Use of a monoclonal anti-estrogen receptor antibody in the immunohistochemical evaluation of human tumors. Cancer Res 1986; $\mathbf{4 6}$ (8 Suppl):4244s-8s.

166. Harvey JM, Clark GM, Osborne CK, et al. Estrogen receptor status by immunohistochemistry is superior to the ligand binding assay for predicting response to adjuvant endocrine therapy in breast cancer. J Clin Oncol 1999:17:1474-81.

167. Thomas JS, Hanby AM, Pinder SE, et al; on behalf of the Sloane Project Steering Group. Implications of inconsistent measurement of ER status in non-invasive breast cancer: a study of 1684 cases from the Sloane Project. Breast J 2008;14:31-6.

168. Baqai T, Sousha S. Oestrogen receptor negativity as a marker for high grade ductal carcinoma in situ of the breast. Histopathology 2003:42:440-7.

169. Otteson GL, Christesen IJ, Larsen JK, et al. Carcinoma in situ of the breast: correlation of hstopathology to immunohstochemical markers and DNA ploidy. Breast Cancer Res Treat 2000:60:219-26.

170. Bryan BB, Schnitt SJ, Collins LC. Ductal carcinoma in situ with basal-like phenotype: a possible precursor to invasive basal-like breast cancer. Mod Pathol 2006:19:617-21.

171. Dabbs DJ, Chivukula M, Carter G, et al. Basal phenotype of ductal carcinoma in situ: recognition and immunohistologic profile. Mod Pathol 2006:19:1506-11. 